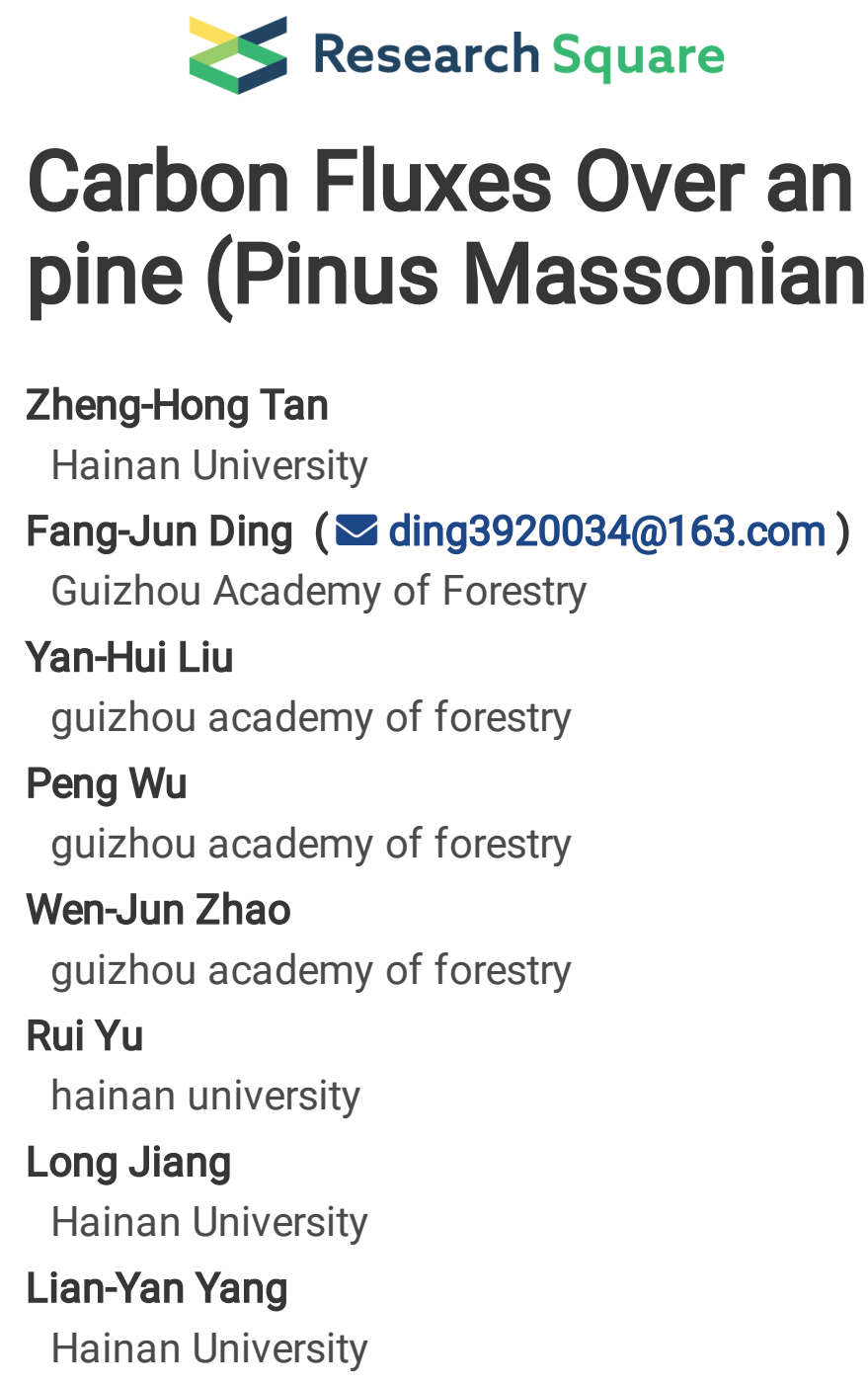

\author{
Hainan University \\ Fang-Jun Ding ( $\nabla$ ding3920034@163.com ) \\ Guizhou Academy of Forestry \\ Yan-Hui Liu \\ guizhou academy of forestry \\ Peng Wu \\ guizhou academy of forestry \\ Wen-Jun Zhao \\ guizhou academy of forestry \\ Rui Yu \\ hainan university \\ Long Jiang \\ Hainan University \\ Lian-Yan Yang \\ Hainan University
}

Zheng-Hong Tan

\title{
Carbon Fluxes Over an Even-Aged Pure Masson pine (Pinus Massoniana) Stand
}

\section{Research}

Keywords: eddy covariance, stomatal conductance, carbon sink, photosynthesis, seasonality

Posted Date: October 20th, 2020

DOI: https://doi.org/10.21203/rs.3.rs-91936/v1

License: (c) (i) This work is licensed under a Creative Commons Attribution 4.0 International License.

Read Full License 
2 Title

3 Carbon fluxes over an even-aged pure Masson

4 pine (Pinus massoniana) stand

5 Zheng-Hong Tan 1,II, Fang-Jun Ding 2, $\mathbb{I I}^{*}$, Yan-Hui Liu ${ }^{2}$, Wu Peng ${ }^{2}$, Wen-Jun Zhao ${ }^{2}$, Rui Yu ${ }^{1}$, 6 Long Jiang ${ }^{1}$, Lian-Yan Yang ${ }^{1, \mathbb{I}}$

71 Ecology Program, School of Ecology \& Environment, Hainan University, Haikou 570228, China

82 Guizhou Academy of Forestry, Guiyang 550005, China

$9 \quad * \quad$ Correspondence: ding3920034@163.com

10 II These authors contributed equally to this study. 
12 Abstract: Masson pine (Pinus massoniana) is a tree species widely planted in central and south 13 China. In the present pioneer study, we reported about our two years of carbon flux 14 observations over an even-aged pure Masson pine stand. Light intensity could explain nearly 15 half (47\%) of the variance in daytime net ecosystem exchange (NEE). Daytime dark respiration 16 was lower than nighttime NEE, suggesting a possible effect of light inhibition on respiration. 17 The mean annual NEE was $-557 \mathrm{~g} \mathrm{C} \mathrm{m}^{-2} \mathrm{yr}^{-1}$, which indicated that this stand is a medium to 18 large carbon sink. This NEE estimates were defensive because we checked the data with thorough quality controls and in consistency with previous independent estimates. An unexpected seasonal pattern of NEE was observed with a clear reduction around the transitional period between summer and autumn (around July). This NEE reduction is probably a consequence of water stress induced stomatal control, and not of a decrease in light intensity. The updated optimal stomatal theory did not provide the best description of stomatal control in relation to photosynthesis. Whether this is a new emergent property of the ecosystem scale needs further investigation.

Keywords: eddy covariance, stomatal conductance, carbon sink, photosynthesis, seasonality 


\section{Introduction}

According to the $7^{\text {th }}$ National Forest Resource Inventory, Masson pine (Pinus massoniana) ranks $1^{\text {st }}$ in the list of trees planted in China (ca. $\left.1.5 \times 10^{5} \mathrm{~km}^{2}\right)$ (State Forestry Administration). As a pioneer tree species, Masson pine can grow well in bare land on nutrient-poor sandy soils. A couple of reasons have contributed to its popularity in Central and South China, including the ability to survive under different crucial environments, no need for additional management, fast growth, and its native distribution in China (Figure 1).

China did not engaged the International Biosphere Program (IBP). When the succeed IGBP (International Geosphere-Biosphere Program) launched in 1987, China actively engaged in this international collaboration study. This led to a boom of ecosystem production studies during the 1980s-90s. In the IGBP period, most of the studies on forest ecosystems carried out in China used the biometric method which developed in IBP ${ }^{[5]}$. This method does not require expensive instruments and is technically simple. On the other hand, besides its destructive and labor-intensive nature, one of the scientific constraints of this method is that it cannot serve for mechanism analysis. This method provides a static annual estimate of ecosystem production (usually net primary production) without knowing the photosynthesis and respiration components and their environmental controls.

The eddy covariance technique, which is based on the theory of turbulent mass and energy transport, became popular in the $1990 \mathrm{~s}^{[6]}$. This method could overcome the deficiency of the biometric method by providing high temporal ecosystem-atmosphere fluxes without inducing significant disturbance. Nonetheless, eddy flux observations have not been carried out in a pure Masson pine stand in the past years.

The aim of the present study was to fill the knowledge gap on eddy flux in pure stands of Masson pine as well as to answer a series of questions regarding the carbon flux in these stands by assessing the mean annual net ecosystem exchange (NEE), photosynthesis and respiration components that balance the NEE, and environmental controls of carbon fluxes. In our following studies, we plan to focus on evapotranspiration and water budget, canopy microclimate, and water use efficiency in pure Masson pine stands.

\section{Materials and methods}

\subsection{Site}

This study was carried out at a field site located in Dushan County (25.825 N,107.503 E, Figure 1), South Guizhou, China, and managed by the Guizhou Academy of Forestry. The dominant climate of the area is subtropical monsoon climate with a clear difference among seasons. The mean annual temperature is approximately $15^{\circ} \mathrm{C}$, and the mean annual rainfall is $1429 \mathrm{~mm}$. Vegetation under the eddy flux tower is an even aged pure Pinus massoniana stand which was planted in 1990. The tree density is approximately 800-1000 stems per hectare. The mean diameter and canopy height are around $28 \mathrm{~cm}$ and $20 \mathrm{~m}$, respectively ca. 2020 .

The flux tower was equipped like a typical eddy flux site. Besides the eddy covariance system (EC), it also contained a couple of sensors that consisted of profile systems and an energy balance system. Because no alternating current was available in the study site, we 
adopted the open-path EC driving by solar energy for the study. We used the open-path EC model EC150 (Campbell Scientific Inc., Logan, UT, USA), which was installed at the height of $30 \mathrm{~m}$ above the ground. The sampling frequency for EC was the usual $10 \mathrm{~Hz}$, which was controlled by a data logger (model CR3000, Campbell Scientific, USA).

The profile system can be separated into two parts, the above- and below-ground profile. For the above-ground profile, we measured the humidity and temperature (sensor type: HMP45C, Campbell Scientific Inc., USA), wind speed (sensor type: 014A-L, Met One, Campbell Scientific Inc., USA), and photosynthetically active radiation (sensor type: LI-190SB, Li-Cor, USA) at the heights of 30, 24, 19, 10, 6, and $3 \mathrm{~m}$. For the below-ground profile, we measured soil temperature (sensor type: 105T, Campbell Scientific Inc., USA) and volumetric soil water content (sensor type: CS616, Campbell Scientific Inc., USA) at the depths of 5, 10, 20, 40 , and $60 \mathrm{~cm}$.

A radiometer that accounts for downward and upward short-wave and long-wave radiation was used to measure and derive net radiation $(\mathrm{Rn})$ (sensor type: CNR2, Apogee, USA). The soil heat flux (G) was measured using a plate flux sensor (sensor type: HFT3, Campbell Scientific Inc., USA). The net balance between Rn and G was used to examine sensible and latent heat fluxes under the principle of energy conservation.

\subsection{Data processing}

Eddy fluxes (i.e., carbon flux, latent heat flux, sensible heat flux, and momentum flux) were calculated as covariance between vertical wind velocity and target scalars with an averaging period of $30 \mathrm{~min}^{[7]}$. We carried out coordinate rotation and WPL corrections to the flux data with the source code written by Xuhui Lee of Yale University. Net ecosystem exchange (NEE), which indicates the carbon sink or source strength for a target ecosystem, was calculated as the sum of eddy transferred carbon flux (Fc) and storage flux (Fs). Fs was calculated using $\mathrm{CO}_{2}$ concentration recordings ${ }^{[8]}$.

We discarded the NEE over $30 \mu \mathrm{mol} \mathrm{m} \mathrm{m}^{-2} \mathrm{~s}^{-1}$ or under $-50 \mu \mathrm{mol} \mathrm{m} \mathrm{m}^{-2} \mathrm{~s}^{-1}$ as well as latent heat flux over $800 \mathrm{wm}^{-2}$ and under $-200 \mathrm{w} \mathrm{m}^{-2}$ as hard spikes. After removing the hard spikes, we adopted a rule in which values more than three times higher than the $95 \%$ confidential interval at the same time point were considered outliers, with a window size of 10 days.

The calm air-related nighttime flux underestimation was corrected using the $u^{*}$ filtering method $\left(u^{*} \text { indicates friction velocity }\right)^{[9]}$. As shown in the results section, we adopted $u^{*}$ threshold value of $0.25 \mathrm{~m} \mathrm{~s}^{-1}$ for our study. We omitted all values on NEE below this threshold value for both daytime and nighttime flux. The present study differed from previous studies because they have only considered nighttime flux $\mathrm{u}^{*}$ filtering.

In order to obtain the defensible annual sum for NEE, we filled the data gap caused by instrument failure, spike detection/omission, and $\mathrm{u}^{*}$ filtering with nonlinear regression. We adopted a modified daytime data model from Lasslop and a nighttime data model from van't Hoff[10,11]. The van't Hoff model is expressed as follows:

$$
\mathrm{NEE}_{\text {nighttime }}=\mathrm{Ae}^{\mathrm{BT}}
$$

where $\mathrm{A}$ and $\mathrm{B}$ are fitted parameters, and $\mathrm{T}$ is temperature, here specified to air temperature at $30 \mathrm{~m}$ height.

The Lasslop model was based on a rectangular hyperbola as follows[10]:

$$
\mathrm{NEE}_{\text {daytime }}=-\frac{\alpha \mathrm{P}_{\mathrm{m}} I}{\alpha I+\mathrm{P}_{\mathrm{m}}}+\mathrm{R}_{\mathrm{d}}
$$

where $\alpha$ is apparent quantum yield, $\mathrm{P}_{\mathrm{m}}$ is light saturated photosynthesis rate, $I$ is light intensity (in this case specified to solar radiation), and $\mathrm{R}_{\mathrm{d}}$ is dark respiration. In the original 
version of Lasslop ${ }^{[10]}$, they related $\mathrm{P}_{\mathrm{m}}$ to water vapor deficit $(\mathrm{D})$ to exhibit a decline in Pm above $1 \mathrm{kPa}$. We excluded this term for two major reasons. The first was that very few data points were observed under $\mathrm{D}$ above $1 \mathrm{kPa}$. In addition, the inclusion of this term has limited impact on the fitted results (cf. Figure s1). The second reason was that introducing one more variable will inevitably lead to numerical instability in curve fitting. Finally, we modified Lasslop et al. (2010) into the following equation:

$$
\mathrm{NEE}_{\text {daytime }}=-\frac{\alpha \mathrm{P}_{\mathrm{m}} \mathrm{I}}{\alpha \mathrm{I}+\mathrm{P}_{\mathrm{m}}}+\mathrm{Ae}^{\mathrm{BT}}
$$

Clearly, this is a combination of a rectangular hyperbola and van't Hoff model. In general, this model was numerically stable when applied to our datasets.

In order to calculate gross primary production (GPP), we adopted the daytime flux partition method, as suggested by Lasslop ${ }^{[10]}$. The GPP was calculated as:

\section{$\mathrm{GPP}=-\left(\mathrm{NEE}-\mathrm{R}_{\mathrm{d}}\right)$}

where $\mathrm{Rd}$ is dark respiration derived from the light response, which equals to $\mathrm{Ae}^{\mathrm{BT}}$.

\subsection{Stomatal controls on carbon fluxes}

We calculated the surface conductance (Gs) by inverting the Penman-Monteith equation (for details see $\mathrm{cf}^{[12]}$ ). Because the studied forest with a stand age of 30 years had a closed canopy, we selected the dry canopy Gs (determined in observations when there was no rainfall in the past three hours) to calculate bulk stomatal conductance ${ }^{[13]}$.

According to the Ball-Berry stomatal model[14], GPP can be expressed as a function of Gs as follows:

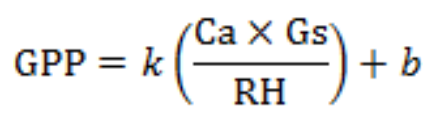

where $\mathrm{RH}$ is relative humidity, Gs is bulk stomatal conductance, $\mathrm{Ca}$ is ambient $\mathrm{CO}_{2}$ concentration, and $k$ and $\mathrm{b}$ are parameters in this linear relationship.

After some modifications of the Leuning model and combination with Fick's law, GPP can also be expressed as ${ }^{[15]}$ :

\section{$\mathrm{GPP}=k[\mathrm{Ca}(\mathrm{Gs} \times \mathrm{D})]+b$}

where $\mathrm{D}$ indicates leaf to air water vapor deficit.

The optimal stomatal theory has suggested the following relationship ${ }^{[16]}$ :

$$
\mathrm{Gs}=\mathrm{G}_{0}+\left(1+\frac{\mathrm{G}_{1}}{\sqrt{\mathrm{D}}}\right) \frac{\mathrm{GPP}}{\mathrm{Ca}}
$$

where $G_{0}$ and $G_{1}$ are the fitted parameters. The term ${ }^{\frac{G_{1}}{\sqrt{D}}}$ is always $>1$, and it tends to dominate the term $\left(1+\frac{\mathbf{G}_{1}}{\sqrt{\mathrm{D}}}\right)_{[16]}$. Therefore, GPP can be expressed as:

$$
\mathrm{GPP}=k(\mathrm{Ca} \times \mathrm{Gs} \times \sqrt{\mathrm{D}})+b
$$

where $k$ and $\mathrm{b}$ are linear parameters, as shown above. 
We also calculated the Jarvis and McNaughton decoupling factors $(\Omega)^{[17]}$. The $\Omega$ varied between 0 and 1 . When $\Omega$ approached 1, canopy was fully decoupled from overhead atmosphere, and evapotranspiration was dominated by available energy.

Notably, the decoupling factor could be related to the crop water stress index (CWSI) proposed by Jackson ${ }^{[18]}$, in case Gs approximates infinity (cf. detailed equation inferring in Supplementary Material):

$$
\Omega=1-\text { CWSI } .
$$

\section{Results}

\subsection{Microclimate}

Temporal variation of major climatic factors presented in Figure 2 show that there are clear daily and seasonal patterns of photosynthetically active radiation (PAR), air temperature (Ta), and water vapor deficit (D). The daily peak PAR was around $1600 \mu \mathrm{mol} \mathrm{m}^{-2} \mathrm{~s}^{-1}$ during summer (June to August) (Figure 2a), and it dropped to 800-1000 $\mathrm{mmol} \mathrm{m}^{-2} \mathrm{~s}^{-1}$ in winter and spring. This seasonal change was probably majorly determined by the Sun-Earth geometry, and it might affect the dynamics of carbon assimilation by photosynthesis. The air temperature dropped below zero during winter and early spring, whereas the highest value during summer reached $30^{\circ} \mathrm{C}$. The daytime temperature during summer was generally higher than $20{ }^{\circ} \mathrm{C}$. The highest $\mathrm{D}$ (above $2.5 \mathrm{kPa}$ ) was found in autumn. In most cases, nighttime D was rarely higher than $0.5 \mathrm{kPa}$. Throughout the year, only $7.38 \%$ of half-hourly $\mathrm{D}$ was higher than $1 \mathrm{kPa}$. A clear daily or seasonal pattern of wind speed (u) was not observed. Histogram analysis (figure not shown) indicated that over $77 \%$ of $\mathrm{u}$ varied between 1 and $4 \mathrm{~m} \mathrm{~s}^{-1}$. Annual mean wind speed was $2.70 \pm 0.87 \mathrm{~m} \mathrm{~s}^{-1}$. The mean wind speed was $2.48 \pm 0.83 \mathrm{~m} \mathrm{~s}^{-1}, 2.85 \pm 0.84$ $\mathrm{m} \mathrm{s}^{-1}$, and $2.80 \pm 0.89 \mathrm{~m} \mathrm{~s}^{-1}$ for the periods of 01:00-06:30, 09:00-17:00, and 19:00-24:00, respectively.

\subsection{Carbon fluxes}

As shown in the half-hourly value, there was a clear seasonality of both daytime and nighttime NEE (Figure 3). In general, both daytime photosynthesis and nighttime respiration were higher in summer and autumn than in winter and spring. Daytime photosynthesis was found to exhibit low values in July and August of both 2012 and 2013. Two major gaps in our data were caused by instrument failure which lasted for nine (September $6^{\text {th }}$ to $14^{\text {th }}, 2012$ ) and 49 days (November 28 2013 to January 17th 2014 ). The total data gap ratio was $59.32 \%$ after spike omission and $\mathrm{u}^{*}$-filtering.

The manner in which nighttime NEE increases with $\mathrm{u}^{*}$ can be roughly expressed by an equation that describes exponential growth to maximum (Figure 4). In the present study, the nighttime NEE (respiration rate) stabilized at approximately $2 \mu \mathrm{mol} \mathrm{m} \mathrm{m}^{-2} \mathrm{~s}^{-1}$. Sixteen bins were distributed as $\mathrm{u}^{*}<0.25 \mathrm{~m} \mathrm{~s}^{-1}$ for a total of 37 bins. This indicated that $43.24 \%$ of the nighttime data were omitted through $\mathrm{u}^{*}$-filtering. The calm air-induced NEE underestimation can occur irrespective of daytime or nighttime; thus, we also removed daytime NEE values when $\mathrm{u}^{*}$ was below this threshold.

Light intensity is the dominant controller in daytime NEE, similar to that found in leaf photosynthesis (Table 1 and Figure 5). In contrast to leaf levels, the dark respiration term at the ecosystem scale was significantly larger, which includes respiration terms from leaf, branch, stem, root, and soil organic matter. As enzyme-catalyzed processes, such as respiration, have strong temperature dependency, we included the van't Hoff model into a regular photosynthesis light response model (Equation 3). We predicted that this could improve the goodness-of-fit, but not to a large extent (see the determinant coefficient listed in Table 1). The 
curve fitting was worst for January in both 2013 and 2014. The mean values of $\alpha$, Pmax, and Rd (or A) were $0.0615 \mu \mathrm{mol} \mathrm{m} \mathrm{m}^{-2} \mathrm{~s}^{-1}$ per $\mathrm{w} \mathrm{m}^{-2}, 29.477 \mu \mathrm{mol} \mathrm{m}^{-2} \mathrm{~s}^{-1}$, and $2.068 \mu \mathrm{mol} \mathrm{m}^{-2} \mathrm{~s}^{-1}$ for rectangular hyperbola equation, and $0.0735 \mu \mathrm{mol} \mathrm{m}^{-2} \mathrm{~s}^{-1}$ per w m $\mathrm{w}^{-2}, 29.638 \mu \mathrm{mol} \mathrm{m}^{-2} \mathrm{~s}^{-1}$, and $0.868 \mu \mathrm{mol} \mathrm{m}{ }^{-2} \mathrm{~s}^{-1}$ for modified Losslop model, respectively. The co-control of light intensity and temperature on daytime NEE is shown in Figure $5 b$. The determinant coefficient $\left(r^{2}\right)$ was 0.4702; considering the inevitable random error for eddy flux data, this value was relatively high and indicated the reliability of using this model. Moreover, when we related the simulated value to the observed value, the slope of linear regression was very close to 1.0 (Figure 6). We presume that if this relationship was used for data gap filling, additional uncertainties would not be introduced.

Figure 7 shows the dependency of ecosystem respiration on temperature. The ecosystem respiration obtained from nighttime NEE observations (indicated with orange color) had a similar $\mathrm{Q}_{10}$ value as that obtained from daytime NEE light response (indicated with dark green). Nevertheless, nighttime-based ecosystem respiration is generally higher than daytime-based respiration. This might be a consequence of the Kok effect, which is related to light inhibition of ecosystem respiration and has been reported previously ${ }^{[19]}$.

The NEE values after $u^{*}$-filtering and gap filling are shown in Figure 8. During this study, the ecosystem sequestrated $1068 \mathrm{gC}$ per $\mathrm{m}^{2}$ ground. The ecosystem acted as a net carbon sink for all observed months. At the seasonal scale, there are two peak carbon sequestration periods: one in the middle of spring (April) and the other in the middle of autumn (August).

\subsection{Surface conductance and its impact on gross ecosystem production}

The half-hourly surface conductance (Gs) and decoupling factors $(\Omega)$ are shown in Figure 9. Gs varied around $5 \mathrm{~mm} \mathrm{~s}^{-1}$, as indicated by the smooth line, and the daily peak Gs was about $20 \mathrm{~mm} \mathrm{~s}^{-1}$. The seasonality of Gs was not very clear. On the other hand, $\Omega$ exhibited clear seasonal variations which were higher in summer and autumn, and lower in winter and spring. This seasonal pattern corresponded to that of NEE (Figure 8). The carbon sequestration was higher when $\Omega$ was higher. As per the definition, higher $\Omega$ indicates that there is a lot of available energy and less stomatal control of evapotranspiration. This means that less stomatal control will benefit carbon sequestration.

The GPP could roughly be expressed as a linear function of Gs in different formats (Figure 10). As GPP and Gs are based on two independent data sources, this relationship suggested that GPP and Gs are two related processes, even at the canopy scale. From a statistical perspective, Fick's law (or Leuning model) $\left(\mathrm{r}^{2}=0.4148\right)$ was better than that in the optimal stomatal theory $\left(\mathrm{r}^{2}=0.3235\right)$ in describing the relationship between photosynthesis and stomatal conductance. We also conducted a simulation test with Ca set at a constant of 380 ppm, which has limited impacts on the relationship and confirmed that Fick's law has statistically better predictions than the optimal stomatal theory.

\section{Discussion and conclusions}

\subsection{Masson pine plantations as substantial carbon sinks}

Per succession of plant communities, Masson pine is a pioneer tree species. The climax of this succession is a subtropical broadleaved evergreen forest. In most cases, stands that are younger than 30 years can be roughly categorized as pioneer stage stands or young forests ${ }^{[20]}$. This classification based on growth stages differed from that based on successional stages, in which 10 years old stands are classified as young stands, 10-40 years old stands are classified as middle-aged stands, and 40+ years old stands are classified as mature forests ${ }^{[21]}$. In case of even-aged pure plantations, the classification based on growth stages might be more suitable than that based on successional stages. 
The studied plantation is at its middle-age growth stage (ca. 22 years old when the eddy flux measuring started). The average NEE was $-557 \mathrm{~g} \mathrm{C} \mathrm{m}^{-2} \mathrm{yr}^{-1}$, which indicated that the plantation is a medium to large carbon sink (Figure 8 ). This value was very close to that reported in a 20-year-old mixed coniferous plantation (553 to $645 \mathrm{~g} \mathrm{C} \mathrm{m}^{-2} \mathrm{yr}^{-1}$ ) in Qianyanzhou (QYZ), Jiangxi, China ${ }^{[22]}$. This mixed coniferous plantation comprised the slash pine, Masson pine, and Chinese fir. Ma compared the vegetation carbon storage and biomass increase between exotic slash pine and Masson pine stands and found no significant differences ${ }^{[23]}$. Our results are also very close to that of the study on 100-year-old mixed pine and broadleaved secondary natural forests $\left(-488 \mathrm{gC} \mathrm{m}^{-2} \mathrm{yr}^{-1}\right)$ in Dinghushan, Guangdong, China ${ }^{[24]}$. The abovementioned results were all estimated based on the eddy covariance technique, and therefore should be comparable. They suggested that Masson pine forests, either in their natural secondary succession, mixed growth with other planted trees, or pure stands, served as medium to large carbon sinks.

As for the other independent estimates, we surveyed the reported $\mathrm{C}$ biomass and its increment. In Hunan Province, China, the Masson pine biomass carbon was $91.8 \mathrm{t} \mathrm{C} \mathrm{ha-}^{-1}$ in a stand age of 20-30 years, with a stand density of 986 stems per hectare ${ }^{[20]}$. Carbon biomass was estimated to be 86.0 t C ha-1 and $112.7 \mathrm{t} \mathrm{C}^{-1}$ in 18 and 28 year old Masson pine plantations, respectively, in Hubei Province, China ${ }^{25]}$. In Sichuan Province, China, Justine reported carbon biomass of 65.88 t $\mathrm{C}$ ha- 1 and 137.99 t $\mathrm{C}$ ha- 1 in 15 and 27-years-old Masson pine plantations ${ }^{[26]}$, respectively. When we divided biomass carbon storage by stand age, the mean biomass increment rate could be reached. The mean annual biomass increment was 367, 477, 402, 439, and $511 \mathrm{~g} \mathrm{C} \mathrm{m-2} \mathrm{for} \mathrm{the} \mathrm{above-mentioned} \mathrm{stands.} \mathrm{These} \mathrm{values} \mathrm{are} \mathrm{close} \mathrm{to} \mathrm{and} \mathrm{slightly} \mathrm{lower}$ than the eddy flux measurements. This confirmed the reliability of the eddy flux measurements. On the other hand, it is clear that reason this stand is a medium to large carbon sink is predominantly because of biomass increment related to tree growth.

We concluded that middle-aged Masson pine plantations (20 - 30 years old) can serve as a medium to large carbon sink with around $400-500 \mathrm{gC} \mathrm{m}^{-2} \mathrm{yr}^{-1}$. This sink strength could be maintained in pure stands, mixed-coniferous forests, or mixed broadleaved forests. Moreover, we concluded that tree growth predominantly contributes to the strength of the investigated carbon sink.

\subsection{Seasonality of net ecosystem exchanges}

Compared to biomass inventory, one of the advantages of eddy covariance is its high temporal resolution fluxes (i.e., $30 \mathrm{~min}$ ) (Figure 8). This provided an alternative way to track the seasonality of fluxes. Our data showed a bimodal pattern of carbon sequestration (Figure 8). The carbon sequestration was unexpectedly lower during the period of the transition from summer to autumn (around July). We compared this seasonal pattern with that of a coniferous plantation comprised partly by Masson pine of similar stand age in Qianyanzhou, Jiangxi, China (Figure s2) ${ }^{[22]}$. Interestingly, a very clear and similar seasonal pattern was also observed in that study. Nevertheless, this pattern was not detected in a 100-year-old mixed broadleaved forest of secondary growth in Dinghushan, Guangdong, China (Figure s2) ${ }^{[24]}$.

We wanted to investigate the possible reasons for the reduction in NEE around July. As NEE is the net balance between GPP and ecosystem respiration, the reduction in NEE could be contributed by either reduction in GPP or by increase in ecosystem respiration. As listed in Table 1 and shown in Figure 8, a sharp increase in daytime based dark respiration (Rd) or night-based ecosystem respiration was not detected around July. In contrast, there was a sharp reduction in the light-saturated photosynthesis rate (Table 1) and in daily peak NEE (Figure 8) around July. Thus, the reduction in NEE was most likely caused by declining GPP.

We illustrated that light intensity (Figure 6) and stomatal conductance (Figure 10) are two major factors controlling ecosystem photosynthesis in the studied stand. After examining the light intensity (Rg) (Figure s2), we excluded it as a major controller causing the NEE reduction 
around July. Notably, there was a clear reduction in $\Omega$ during the period around July in both 2012 and 2013. The term $1-\Omega$ is an approximation of the crop water stress index ${ }^{[18]}$. The reduction in $\Omega$ indicated an increase in water stress (1- $\Omega$ ). The value of $\Omega$ is derived based on the energy flux components, which are independent of carbon fluxes. The synchronization of $1-\Omega$ and NEE suggested that water stress-related stomatal reduction might be the critical reason for NEE reduction around July. This idea also received support from the results of a study conducted in QYZ site in which the researchers attributed carbon sequestration reduction to summer drought ${ }^{[22]}$. It should be noted that the soil water content did not exhibit the lowest value around July (Figure s3). In other words, we were not able to detect ecosystem water stress through soil water observations. We thus recommend the $1-\Omega$ (or CWSI) for water stress analysis at the eddy flux site.

\subsection{Light and stomatal controls of ecosystem photosynthesis}

As abstracted in the FvCB model[27], leaf photosynthesis can be limited either by RuBisCO-catalyzed carboxylation or by light driving electron transport. Because RuBisCO is both a carboxylase and an oxygenase ${ }^{[28]}$, the intercellular $\mathrm{CO}_{2}$ concentration ( $\mathrm{C}$ ) plays a leading role in this carboxylation. Stomatal behavior (openness), which is the major determinant of $\mathrm{c}_{i}$, has a direct impact on photosynthesis. On the other hand, stomatal openness can also affect leaf water potential and leaf temperature, which can in turn influence photosynthesis ${ }^{[29]}$.

From a statistic perspective, both light intensity (Figure 6) and Gs (Figure 10) are important controllers of ecosystem photosynthesis. Nevertheless, it is Gs, and not light intensity, that could account for the decline in photosynthesis around July. This phenomenon led us to think about the extent and way in which light and Gs influence photosynthesis. It has been noted that the impact of environmental factors on ecological processes is not equivalent and additive. In most cases, it follows the law of the minimum, that is, the FvCB model. It is highly possible that Gs was the limiting factor influencing the decline in photosynthesis in July, while the light conditions were adequate.

Ever since the pioneer work of Monteith ${ }^{[30]}$, the light use efficiency model has been widely used for simulating photosynthetic production driven by satellite observations, i.e., the CASA model[31]. The light use efficiency model stresses the importance of absorbed light in photosynthesis, and it is successful in global applications. It is still clear that the control by Gs should not be neglected in these models, at least in models simulating Masson pine photosynthesis in South China.

The way in which Gs influences photosynthesis at the ecosystem level also needs special attention. In the present study, the Gs control on GPP predicted by the optimal stomatal theory was better than that predicted by the Ball-Berry model, but worse than that predicted by the Leuning model (Figure 10). This result was unexpected because the optimal stomatal theory we used was regarded as an updated version of the Leuning model[16]. It is still not clear whether this is a common case or a case specific for the studied stand. Given that this is a common emergent property for canopy scale processes, further studies are needed to clarify the underlying mechanisms.

Acknowledgements: This work was supported by the Guizhou Forest Research Project "The ecological service of Guizhou's Forests" and CFERN \& BEIJING TECHNO SOLUTIONS Award Funds on excellent academic achievements. All data are available upon request from the corresponding author (ding3920034@163.com). We declare that there are no conflicts of interest for this study.

Author Contributions: FJD designed this study, ZHT carried data analysis, ZHT, LYY and FJD drafted the first version of the manuscript. All authors contributed to writing and data interpretation. 
Table 1. Curve fitting results with rectangular hyperbolic equation (RHE, model 1) and modified Lasslop model (Lasslop, model 2). $\alpha$, Pmax, Rd are the apparent quantum yield, light-saturated photosynthesis rate, and dark respiration parameter, respectively. Details of the models are given in the text. $\mathrm{r}^{2}$ is the determinant coefficient, Ta is the mean air temperature in the corresponding period, and $\mathrm{n}$ is the number of data points included in the curve fitting. I.V. indicates an impossible value. N.A. indicates a fail in nonlinear

\begin{tabular}{|c|c|c|c|c|c|c|c|c|c|c|}
\hline \multirow{2}{*}{$\begin{array}{c}\text { Parameters } \\
\text { Model }\end{array}$} & \multicolumn{2}{|c|}{$\alpha$} & \multicolumn{2}{|c|}{$P_{\max }$} & \multirow{2}{*}{$\begin{array}{c}\mathbf{R}_{\mathbf{d}} \\
\mathbf{1}\end{array}$} & \multirow{2}{*}{$\begin{array}{c}\text { A } \\
2\end{array}$} & \multicolumn{2}{|c|}{$\mathbf{r}^{2}$} & \multirow{2}{*}{$\mathrm{Ta}$} & \multirow{2}{*}{$\mathbf{n}$} \\
\hline & 1 & 2 & 1 & 2 & & & 1 & 2 & & \\
\hline Jun-2012 & 0.056 & 0.076 & 68.47 & 55.93 & 1.04 & 0.70 & 0.5259 & 0.5409 & 20.19 & 582 \\
\hline Jul-2012 & 0.042 & 0.067 & 22.62 & 21.57 & 1.20 & 0.59 & 0.3924 & 0.4100 & 23.56 & 569 \\
\hline Aug-2012 & 0.070 & 0.077 & 35.20 & 37.98 & 3.96 & 0.91 & 0.5319 & 0.5440 & 24.54 & 583 \\
\hline Sep-2012 & 0.112 & 0.124 & 31.85 & 35.69 & 5.14 & 1.44 & 0.5474 & 0.5849 & 21.51 & 438 \\
\hline Oct-2012 & 0.049 & 0.067 & 38.67 & 34.06 & 0.34 & 0.49 & 0.4404 & 0.4468 & 17.70 & 457 \\
\hline Nov-2012 & 0.054 & 0.057 & 26.51 & 27.85 & 1.38 & 0.58 & 0.5150 & 0.5216 & 15.83 & 424 \\
\hline Dec-2012 & 0.088 & 0.089 & 18.87 & 21.71 & 2.04 & 1.28 & 0.5709 & 0.5980 & 9.67 & 451 \\
\hline Jan-2013 & 0.022 & 0.034 & 29.21 & 17.50 & I.V. & I.V. & 0.2810 & 0.2789 & 3.24 & 396 \\
\hline Feb-2013 & 0.070 & 0.072 & 13.45 & 17.77 & 1.39 & 1.10 & 0.3723 & 0.4266 & 9.36 & 466 \\
\hline Mar-2013 & 0.062 & 0.086 & 16.27 & 18.71 & 1.66 & 1.28 & 0.4781 & 0.5533 & 12.68 & 488 \\
\hline Apr-2013 & 0.077 & 0.103 & 25.47 & 27.74 & 1.83 & 1.30 & 0.5728 & 0.6105 & 14.74 & 571 \\
\hline May-2013 & 0.061 & 0.124 & 26.62 & 28.89 & 1.47 & 1.51 & 0.4410 & 0.5142 & 19.04 & 579 \\
\hline Jun-2013 & 0.083 & 0.139 & 19.40 & 23.93 & 3.34 & 1.50 & 0.3624 & 0.4513 & 21.85 & 539 \\
\hline Jul-2013 & 0.052 & 0.057 & 18.16 & 19.46 & 2.52 & 0.57 & 0.5193 & 0.5293 & 24.29 & 634 \\
\hline Aug-2013 & 0.043 & 0.022 & 33.73 & I.V. & 3.32 & 0.30 & 0.5702 & 0.5446 & 24.25 & 606 \\
\hline Sep-2013 & 0.060 & 0.065 & 44.29 & 46.58 & 1.62 & 0.51 & 0.5069 & 0.5127 & 22.54 & 494 \\
\hline Oct-2013 & 0.060 & 0.061 & 36.37 & 37.59 & 1.64 & 0.43 & 0.5790 & 0.5821 & 20.82 & 532 \\
\hline Nov-2013 & 0.096 & 0.069 & 20.54 & 23.24 & 2.97 & 0.63 & 0.5448 & 0.5363 & 15.36 & 455 \\
\hline Dec-2013 & 0.050 & 0.062 & 42.26 & 38.45 & 1.89 & 1.35 & 0.6406 & 0.6625 & 11.25 & 275 \\
\hline Jan-2014 & N.A. & N.A. & N.A. & N.A. & N.A. & N.A. & N.A. & N.A. & N.A. & $<100$ \\
\hline Feb-2014 & 0.023 & 0.019 & 21.58 & 28.48 & 0.54 & 0.04 & 0.4553 & 0.4536 & 10.40 & 357 \\
\hline
\end{tabular}


Figure 1. Distribution of Pinus massoniana in Mainland China. This figure was drawn based on Zhou ${ }^{[1]}$, $\operatorname{Lin}^{[2]}$, Zhang ${ }^{[3]}$, and Yan ${ }^{[4]}$. The Taiwan and Sansha regions were not included in this study. On Hainan Island, there are variants of Pinus massoniana which were also not included in the study. The study site is indicated by a red star.

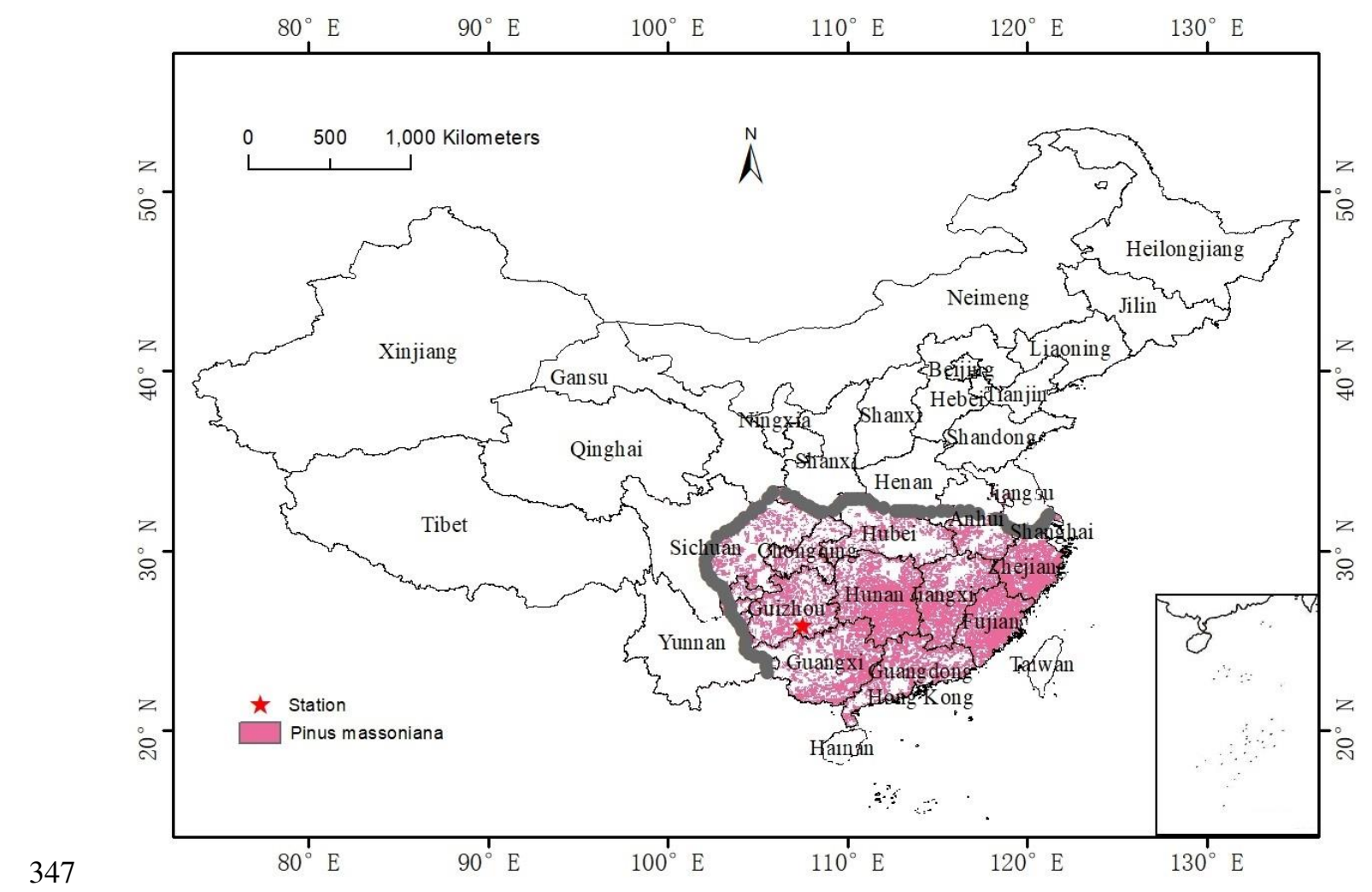


Figure 2. Microclimate of the studied pure Pinus massoniana plantations. (A) photosynthetically active radiation, PAR; (B) air temperature at $30 \mathrm{~m}$ height, Ta; (C) water vapor 349 pressure deficit at $30 \mathrm{~m}$ height, $\mathrm{D}$; (D) and wind speed at $30 \mathrm{~m}$ height, $\mathrm{u}$.
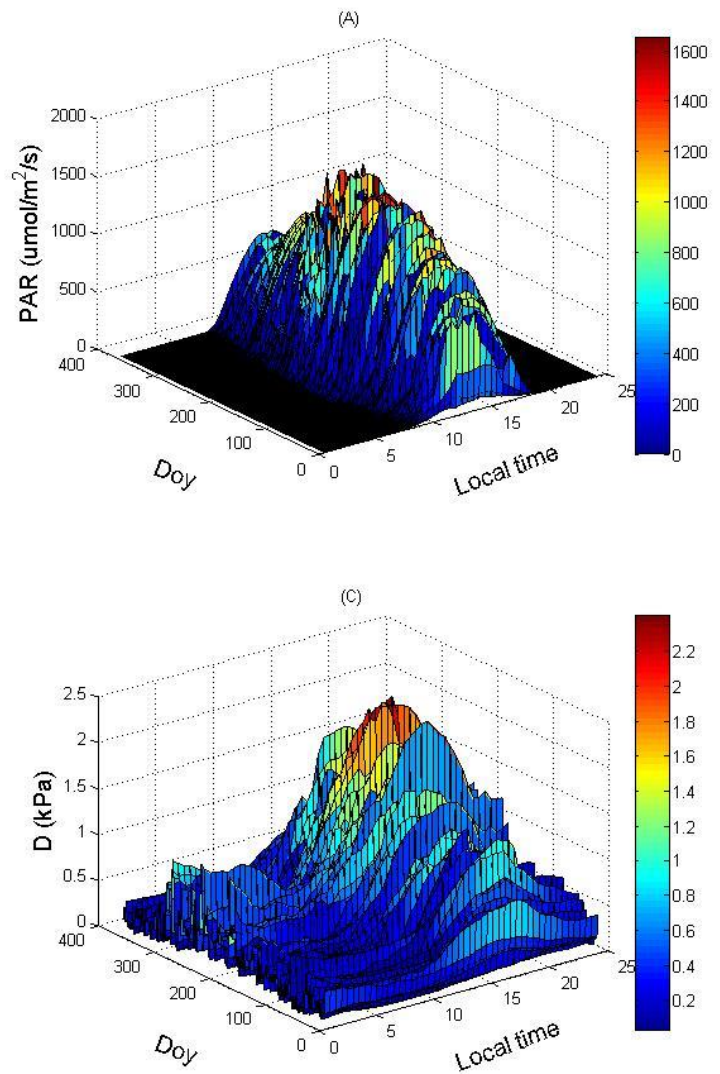
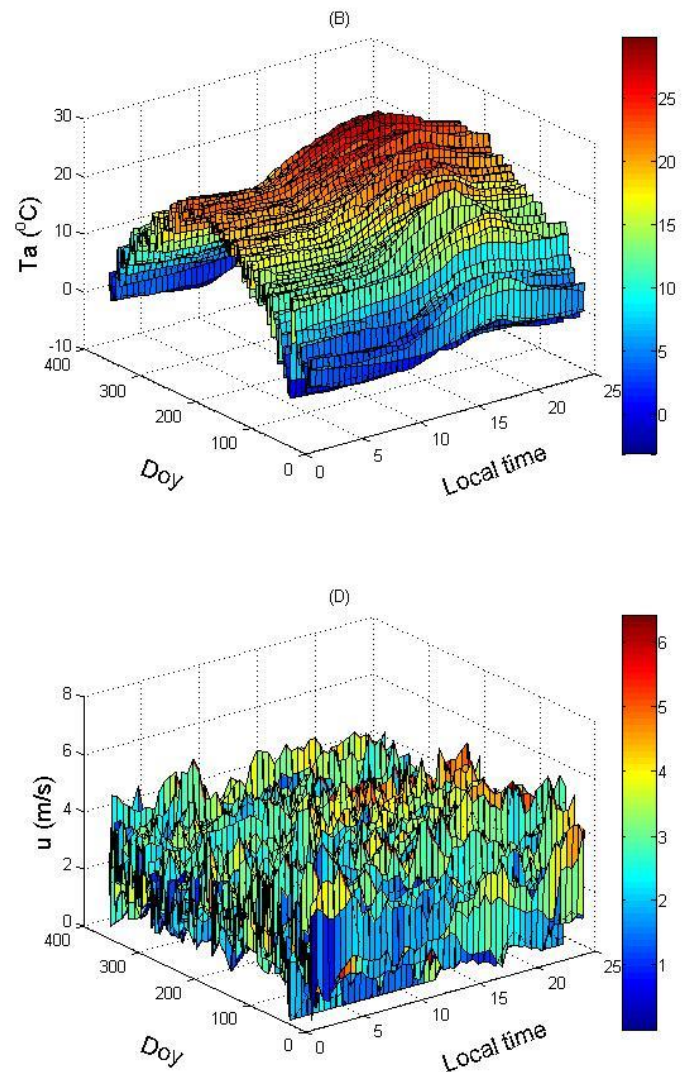


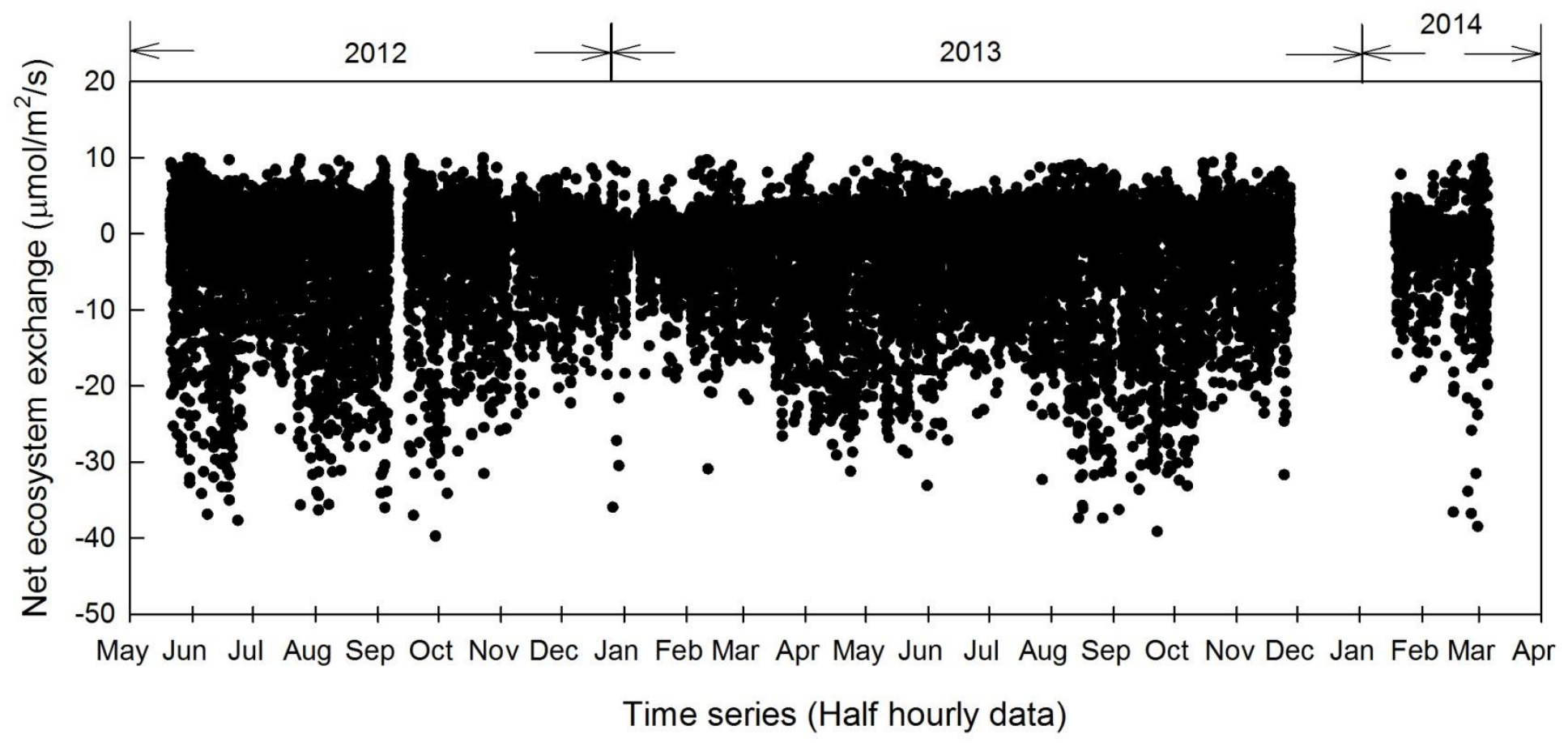


Figure 4. Dependence of nighttime net ecosystem exchange (NEE) on friction velocity $\left(u^{*}\right)$. The data were binned as the same number of data points per bin after sorting as $\mathrm{u}^{*}$. The mean value (black circles) and standard deviation (error bars) of each bin were calculated. An exponential growth to maximum equation was fitted to the dataset.

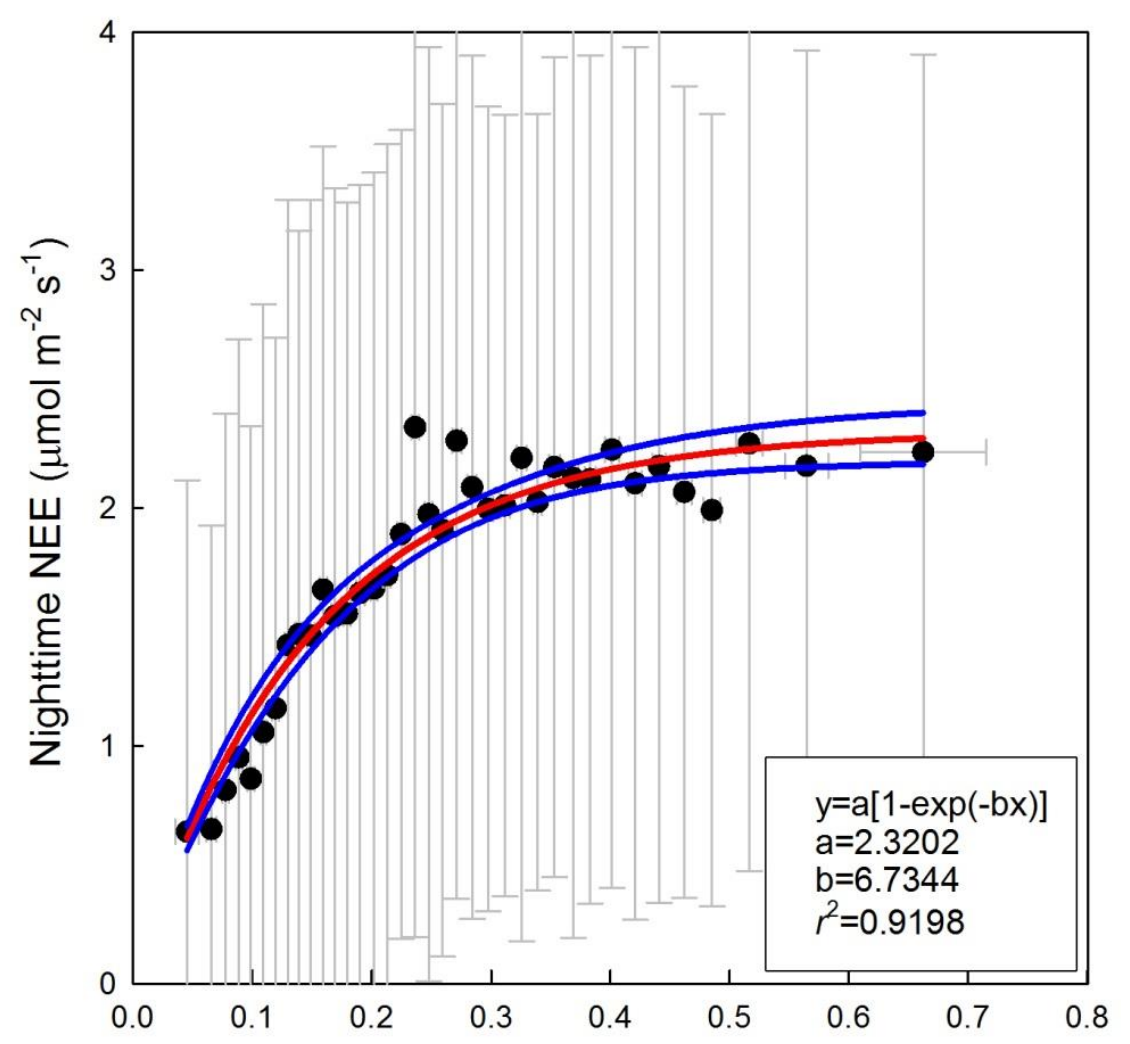

Friction velocity $\left(\mathrm{u}^{*}, \mathrm{~m} \mathrm{~s}^{-1}\right)$ 
362 Figure 5. Co-control of solar radiation (Rg) and air temperature (Ta) on daytime net ecosystem exchange (NEE). Subpanel (a) shows our observations, and (b) shows the 363 simulated results.
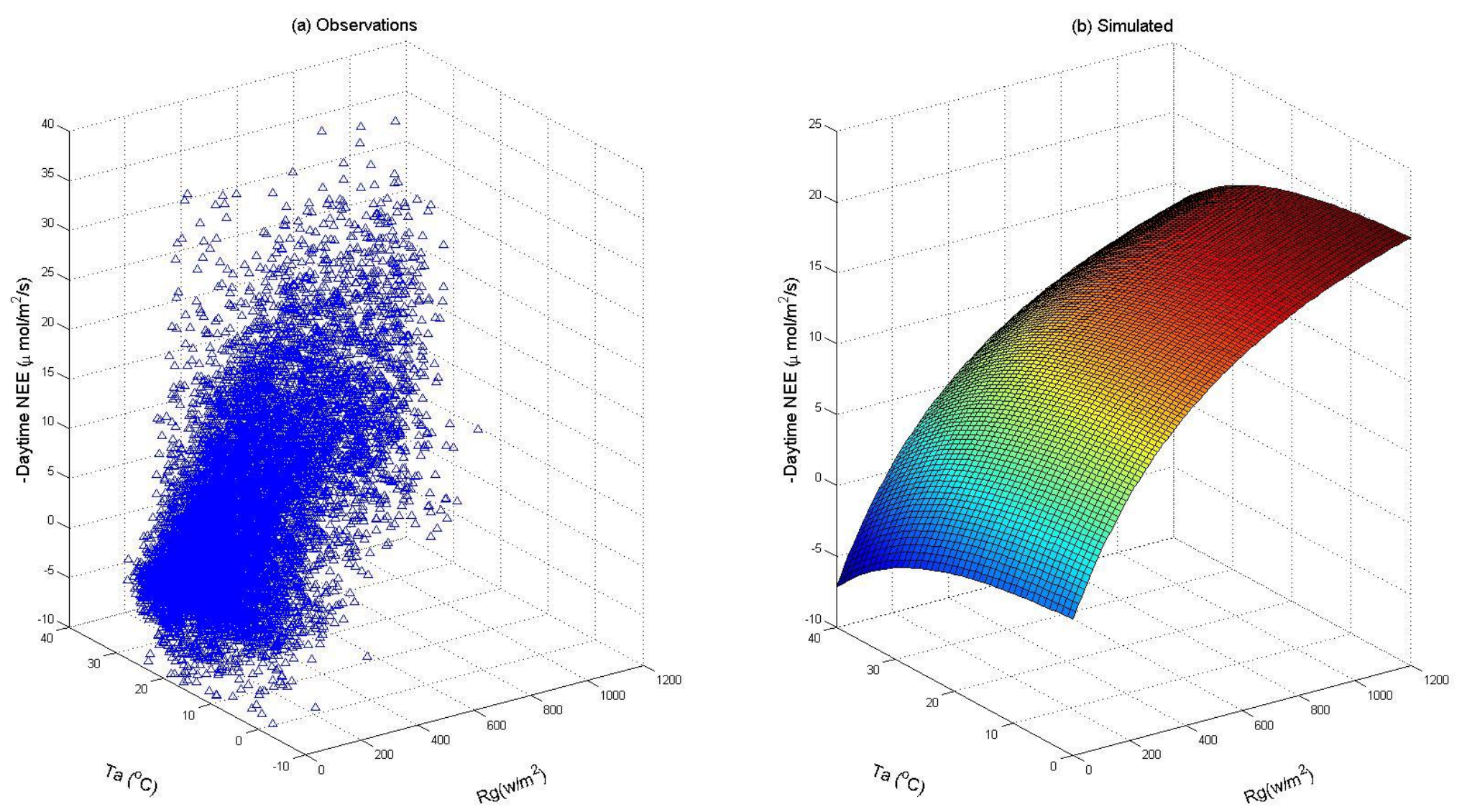


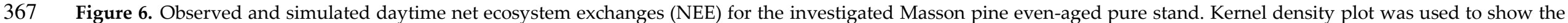
368 distribution of data points. Linear regression was performed as shown by the white line.

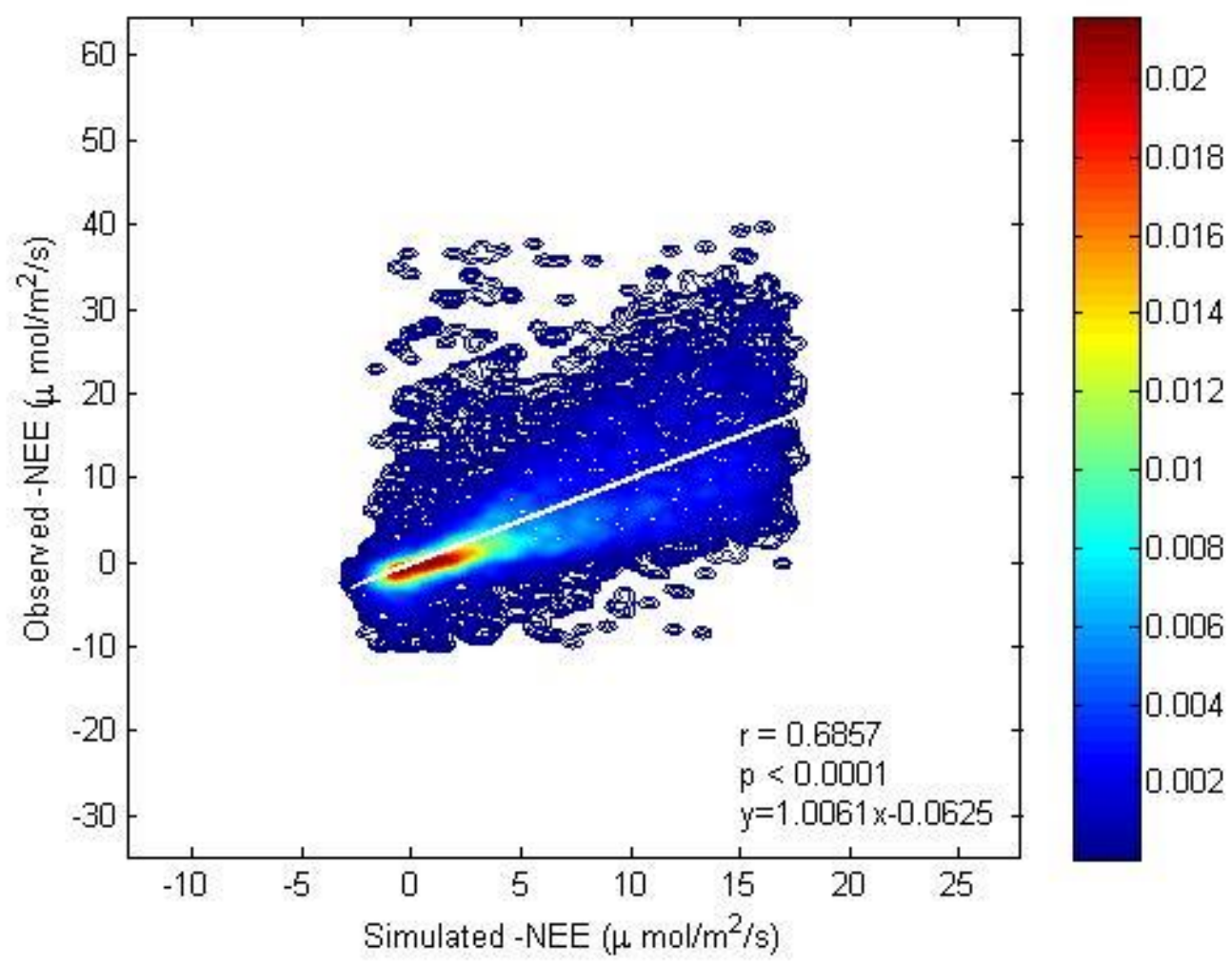


Figure 7. Dependence of daytime dark respiration (green open squares) and nighttime respiration (red solid circles) on air temperature. The van't Hoff model was fitted to the data.

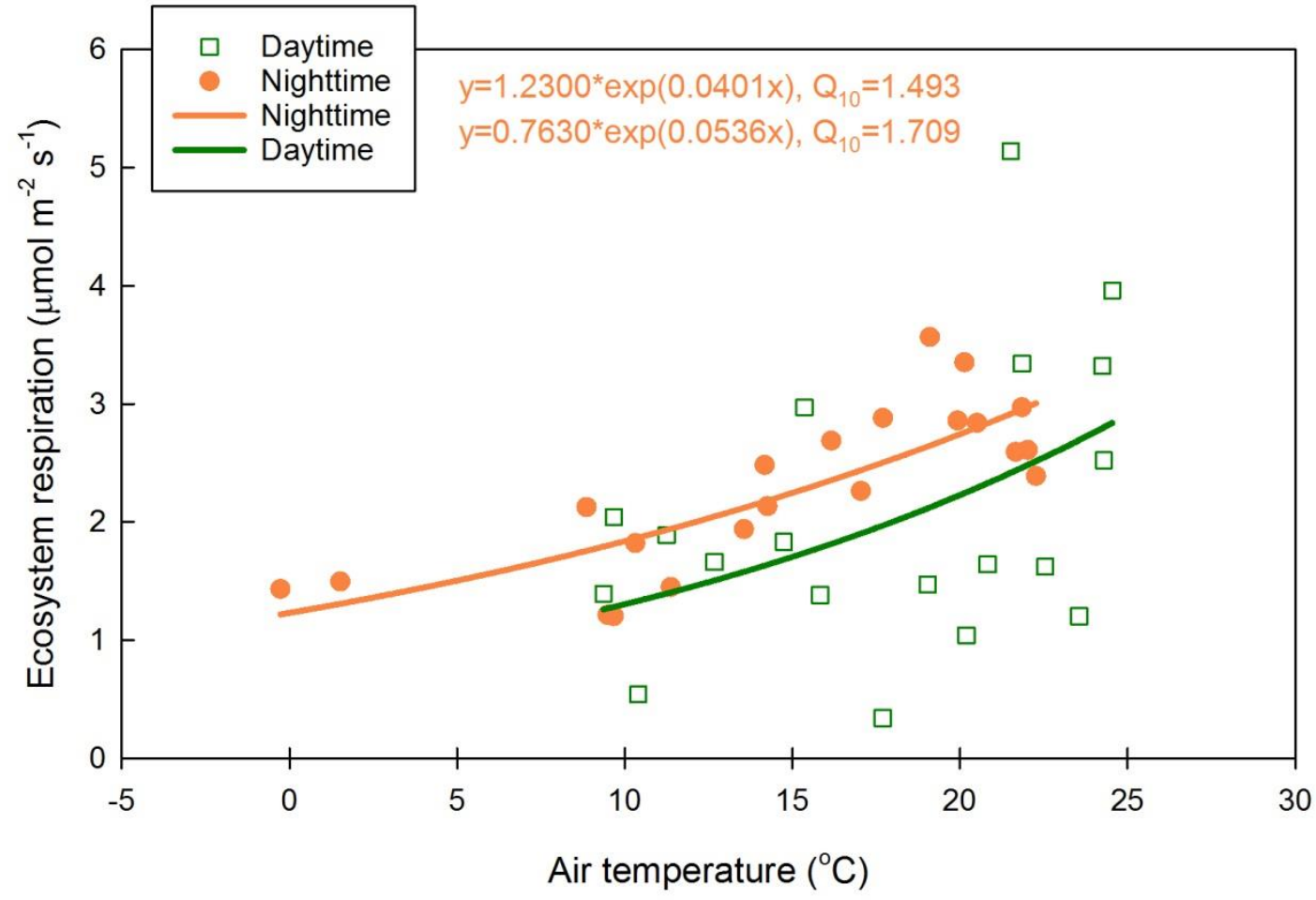


Figure 8. Time series of net ecosystem exchanges after gap filling. The circles show the half-hourly data, and bars with error bars indicate monthly values and their standard deviations.

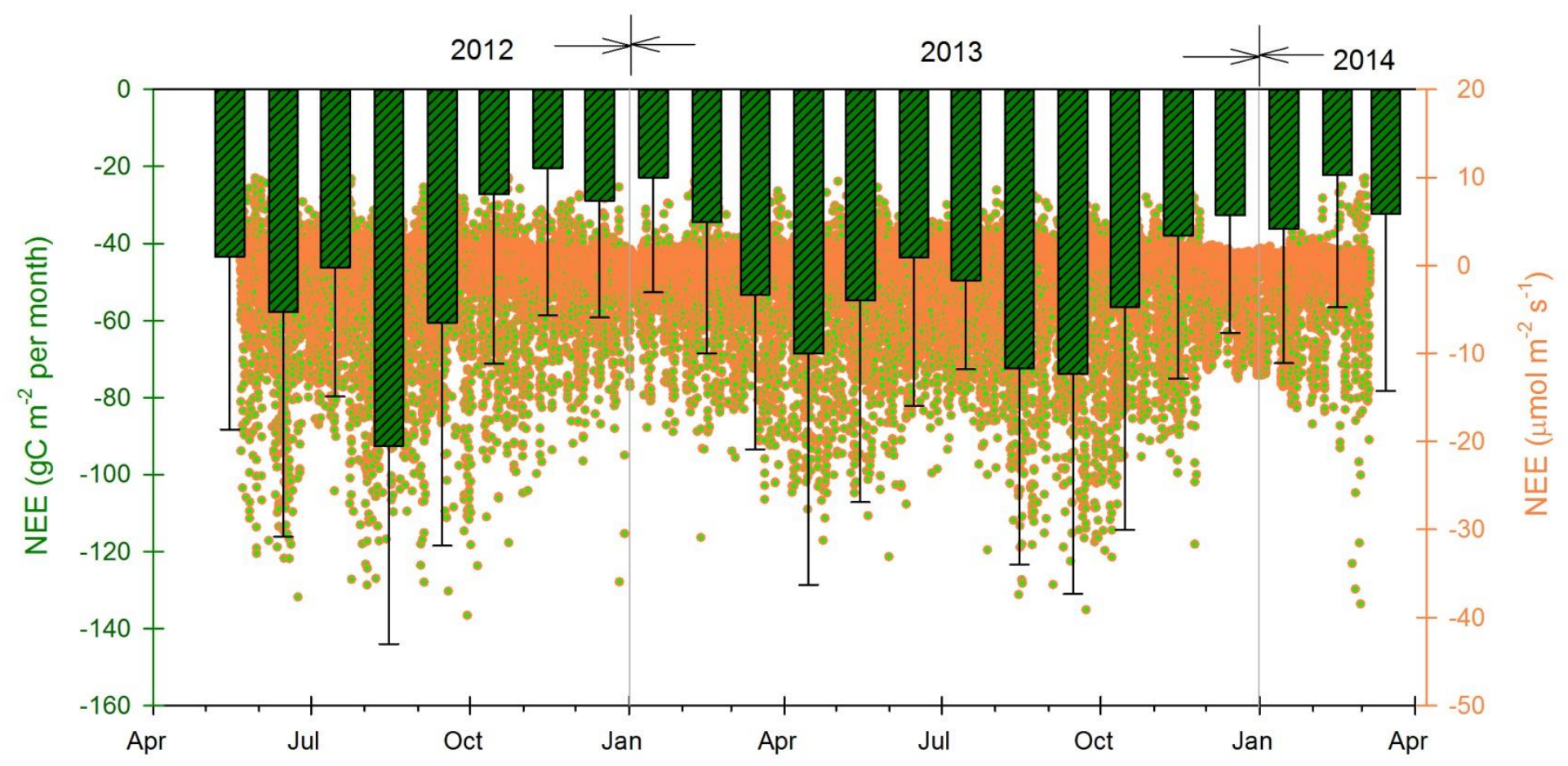



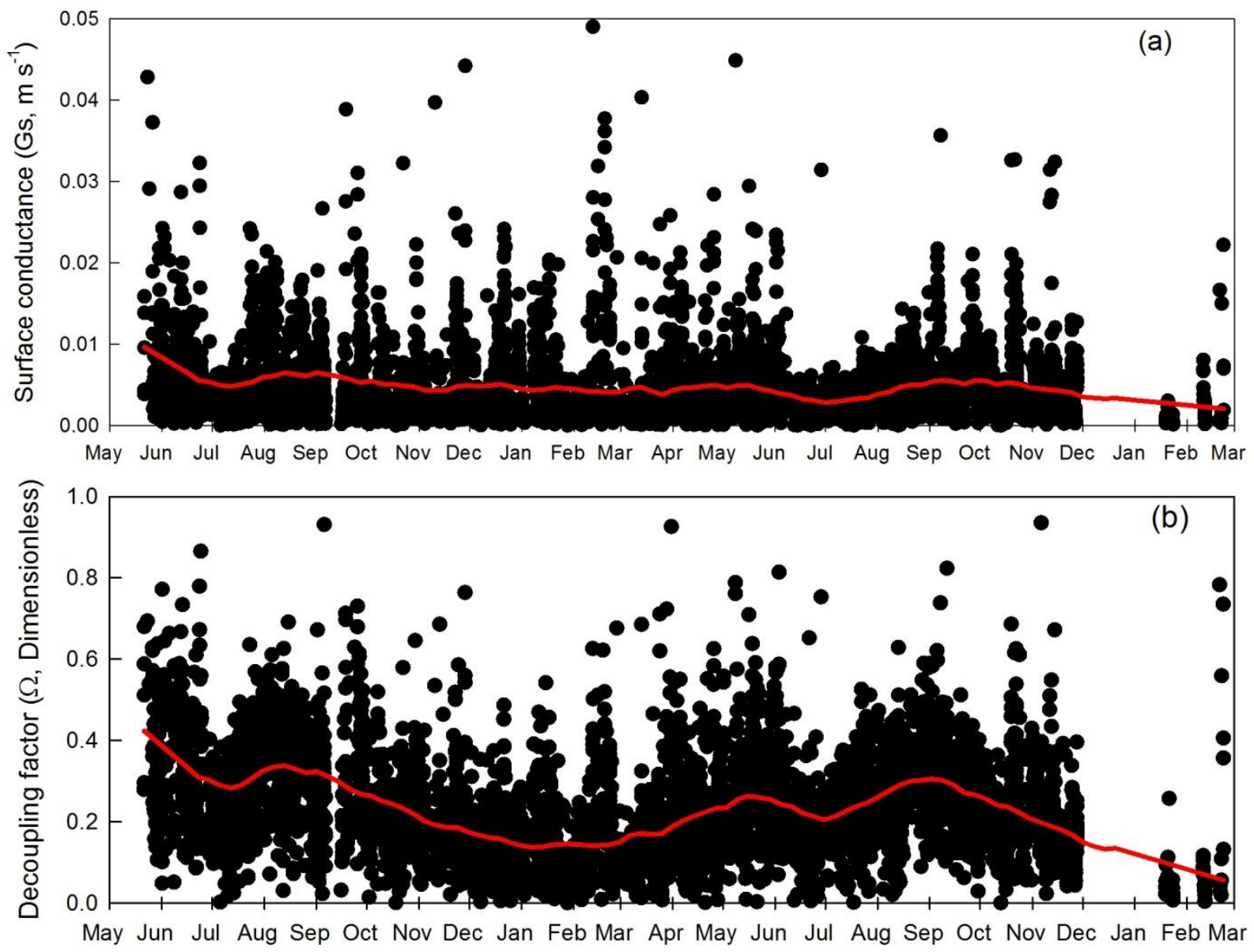

Time series 
Figure 10. Gross primary production (GPP) expressed as a function of surface conductance (Gs) and water vapor deficit (D) or relative humidity (RH). GPP is expressed in $\mu \mathrm{mol} \mathrm{m}^{-2} \mathrm{~s}^{-1}$, Gs is expressed in $\mathrm{m}$ $\mathrm{s}^{-1}, \mathrm{Ca}$ is the ambient carbon dioxide concentration and is expressed in ppm, $\mathrm{RH}$ is expressed in \%, and D is expressed in $\mathrm{kPa}$. Linear regression was applied to the dataset, which is indicated by the black line ((a) $\mathrm{y}=122.6700+5.8480, \mathrm{r}^{2}=0.1967 ;$ (b) $\mathrm{y}=4.6969 \mathrm{x}+4.6071, \mathrm{r}^{2}=0.4148$; (c) $\mathrm{y}=3.9000 \mathrm{x}+4.9045, \mathrm{r}^{2}=0.3235$ ).

(a)
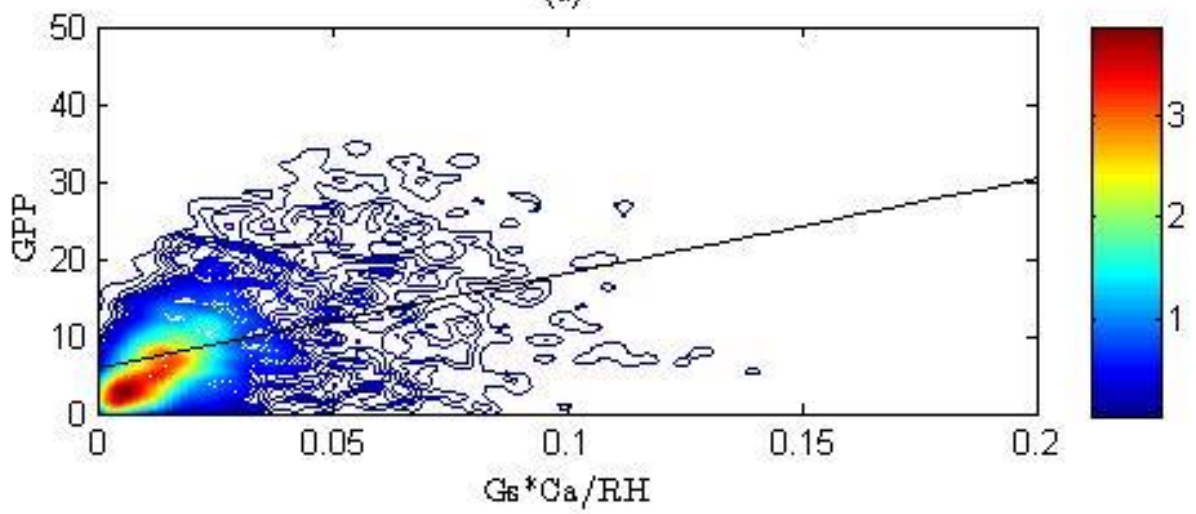

(b)
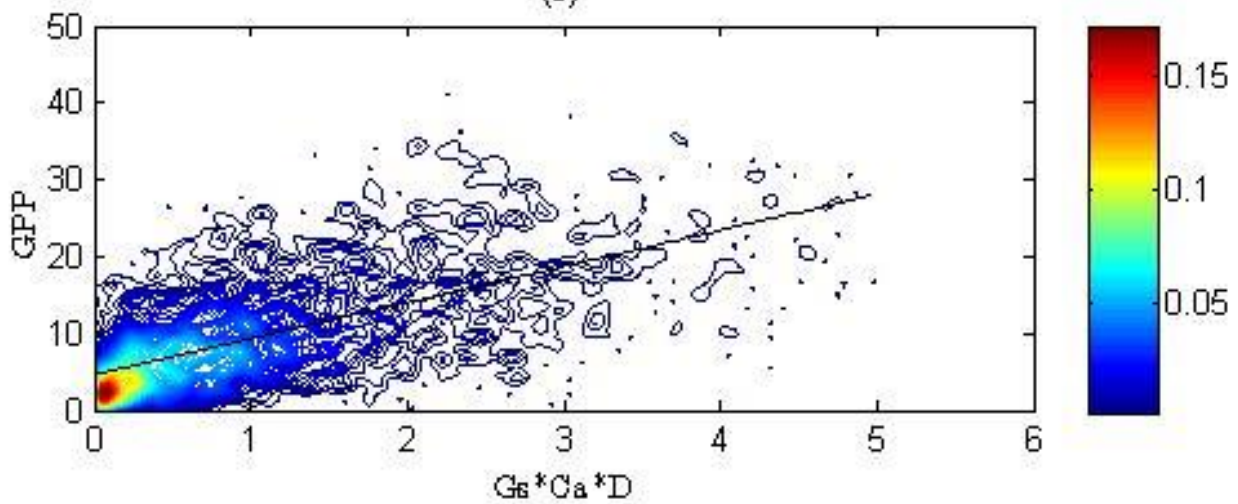

(c)

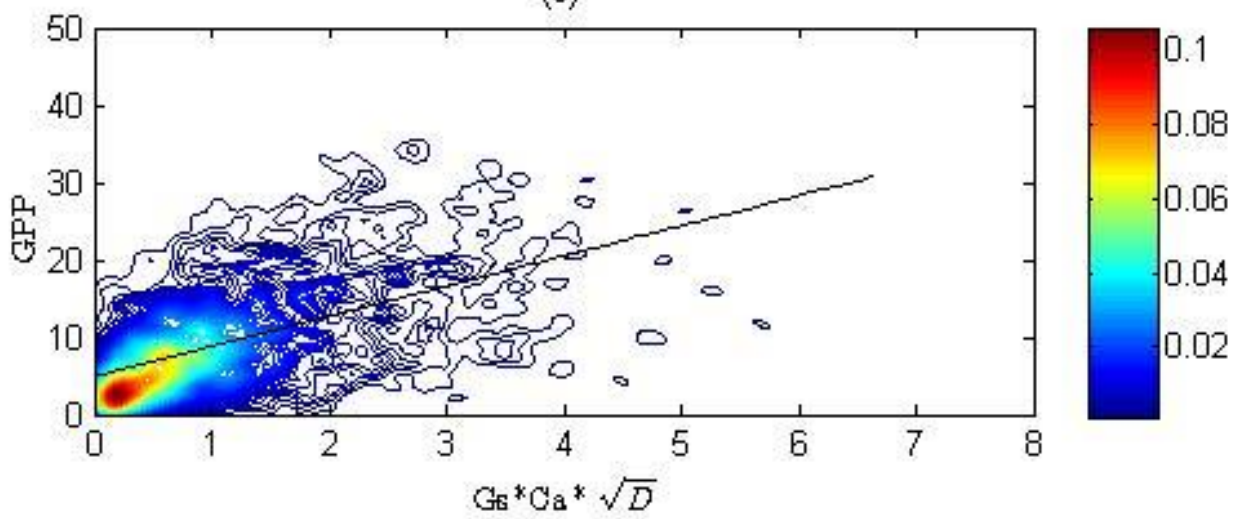

\section{References}

392 1. Zhou ZX (2000) Masson pine in China. China Forestry Press, Beijing, China. pp 15.

393 2. Lin Q, Jin G, Zhang R, Chu D, Qin G, Zhou Z (2016) Provenance variation in growth, stem-form and wood density of Masson pine at 24-year-old and the provenance division. Scientia Silvae Sinica, 45, 55-61. 
3. Zhang XB, Guo LP, Zhao MX, Wang H, Yang G, Jing ZX, Lu YY, Ye L, Ke X, Huang LQ (2016) Production suitability regionalization study of Pinus massoniana. China Journal of Chinese Materia Medica, 41, 3115-3121, Doi: 10.4268/cjcmm20161701.

4. Yan YH, Cen YF, Zhang PY, Zhang Y, Liu X, Li CY, Xu S (2019) Predicting distribution pattern and future change of Pinus massoniana in China based on MaxEnt model. Chinese Journal of Ecology, 38, 2896-2901, doi: 10.13292/j.1000-4890.201909.022.

5. Newbould P (1967) Methods of estimating of primary production of forests. Blackwell Publishing, Oxford, UK.

6. Baldocchi D (1988) Measuring biosphere-atmosphere exchanges of biologically related gases with micrometeorological methods. Ecology, 69, 1331-1340, doi: 10.2307/1941631.

7. Verma, S.B., 1990. Micrometeorological methods for measuring surface fluxes of mass and energy. Remote Sensing Reviews, 5: 99-115.

8. Grace J, Lloyd J, McIntyre J, Miranda A, Meir P, Miranda H, Moncerieff J, Massheder J, Wright I, Gash J (1995) Fluxes of carbon dioxide and water vapour over an undisturbed tropical forest in south-west Amazonia. Global Change Biology, 1, 1-12, doi: 10.1111/j.1365-2486.1995.tb00001.x.

9. Saleska, S.R. et al., 2003. Carbon in Amazon Forests: Unexpected Seasonal Fluxes and Disturbance-Induced Losses. Science, 302: 1554-1557.

10. Lasslop G, Reichstein M, Papale D, Richardson AD, Arneth A, Barr A, Stoy P, Wohlfahrt G (2010) Separation of net ecosystem exchange into assimilation and respiration using a light response curve approach: critical issues and global evaluation. Global Change Biology, 16, 187-208, doi: 10.1111/j.1365-2486.2009.02041.x.

11. van't Hoff, J.H. (1898) Lectures on Theoretical and Physical Chemistry. Part I. Chemical Dynamics (translated by R. A. Lehfeldt), pp. 224-229. Edward Arnold, London.

12. Tan, Z.-H. et al., 2019. Surface conductance for evapotranspiration of tropical forests: Calculations, variations, and controls. Agricultural and Forest Meteorology, 275: 317-328.

13. Kelliher FM, Leuning R, Raupach MR, Shulze ED (1996) Maximum conductances for evaporation from global vegetation types. Agricultural and Forest Meteorology, 73, 1-16, doi: 10.1016/0168-1923(94)02178-M.

14. Ball JT, Woodrow IE, Berry JA (1987) A model predicting stomatal conductance and its contribution to the control of photosynthesis under different environmental conditions. In: Progress in Photosynthesis Research (ed. Biggins J), pp. 221-224. Martinus-Nijhoff Publishers, Dordrecht, the Netherlands.

15. Leuning R (1995) A critical appraisal of a coupled stomatal-photosynthesis model for C3 plants. Plant, Cell and Environment, 18, 339-357.

16. Medlyn B, Duursma RA, Eamus D, Ellsworth DS, Prentice IC, Barton CVM, Crous KY, de Angelis P, Freeman M, Wingate L (2011). Reconciling the optimal and empirical approaches to modeling stomatal conductance. Global Change Biology, 17, 2134-2144, doi: 10.1111/j.1365-2486.2010.02375.x.

17. Jarvis, P.G. and McNaughton, K.G., 1986. Stomatal Control of Transpiration: Scaling Up from Leaf to Region. In: A. MacFadyen and E.D. Ford (Editors), Advances in Ecological Research. Academic Press, pp. 1-49.

18. Jackson, R.D., Idso, S.B., Reginato, R.J. and Pinter Jr., P.J., 1981. Canopy temperature as a crop water stress indicator. Water Resources Research, 17: 1133-1138.

19. Keenan TF, Migliavacca M, Papale D, Baldocchi D, Reichstein M, Torn M, Wutzler T (2019) Widespread inhibition of daytime ecosystem respiration. Nature Ecology and Evolution, 3, 407-415, doi: 10.1038/s41559-019-0809-2.

20. Chen LC, Wang SL, Wang QK (2016) Ecosystem carbon stocks in a forest chronosequence in Hunan province, South China. Plant and Soil, 409, 217-228. doi: 10.1007/s11104-016-2950-x.

21. Chen LC, Wang SL, Wang QK (2016) Carbon stock density in planted versus natural Pinus massoniana forests in sub-tropical China. Annals of Forest Sciences, 73, 461-472, doi: 10.1007/s13595-016-0539-4.

22. Liu YF, Song X, Sun XM, Wen XF, Chen YR (2005) Seasonal variation of CO2 flux and its environmental factors in evergreen coniferous plantation. Science in China, Series D: Earth Sciences, 48, 123-132. 
23. Ma Z, Hartmann H, Wang H, Li Q, Wang Y, Li S (2014) Carbon dynamics and stability between native Masson pine and exotic slash pine plantations in subtropical China. European Journal of Forest Research, 133, 307-321, doi: 10.1007/s10342-013-0763-5.

24. Li YL, Zhou GY, Zhang DQ, Wenigmann KO, Otieno D, Tenhunen J, Zhang QM, Yan JH (2012). Quantification of ecosystem carbon exchange characteristics in a dominant subtropical evergreen forest ecosystem. Asia-Pacific Journal of Atmospheric Science, 48, 1-10, doi: 10.1007/s13143-012-0001-y.

25. Ali Z, Ahmad A, Akhtar K, Teng M, Zeng W, Yan Z, Zhou Z (2019) Patterns of biomass, carbon, and soil properties in Masson pine (Pinus massoniana Lamb) plantations with different stand ages and management practices. Forests, 10, 645, doi: 10.3390/f10080645.

26. Justine MF, Yang W, Wu F, Khan MN (2017) Dynamics of biomass and carbon sequestration across a chronosequence of Masson pine plantations. Journal of Geophysical Research - Biogeosciences, 122, 578-591, doi: 10.1002/2016JG003619.

27. von Caemmerer S (2000) Biochemical models of leaf photosynthesis. Vol 2, CSIRO publishing, Collingwood, Australia.

28. Bowes G., Ogren W.L., Hageman R.H. (1971) Phosphoglycolate production catalyzed by ribulose diphosphate carboxylase. Biochemical and Biophysical Research Communications 45, 716-722.

29. Farquhar GD, Sharkey TD (1982) Stomatal conductance and photosynthesis. Annual Review of Plant Physiology, 33, 317-345, doi: 10.1146/annurev.pp.33.060182.001533.

30. Monteith JL (1972) Solar radiation and productivity in tropical ecosystems. Journal of Applied Ecology, 9, 747-766.

31. Potter CS, Randerson JT, Field CB, Matson PA, Vitousek PM, Mooney HA, Klooster SA (1993). Terrestrial ecosystem production: a process model based on global satellite and surface data. Global Biogeochemical Cycles, 7, 811-841. 32.

32. Alves I, Pereira LS. Non-water-stressed baselines for irrigation scheduling with infrared thermometers: A new approach. Irrigation Science. 2000, 19, 2, 101-106. 


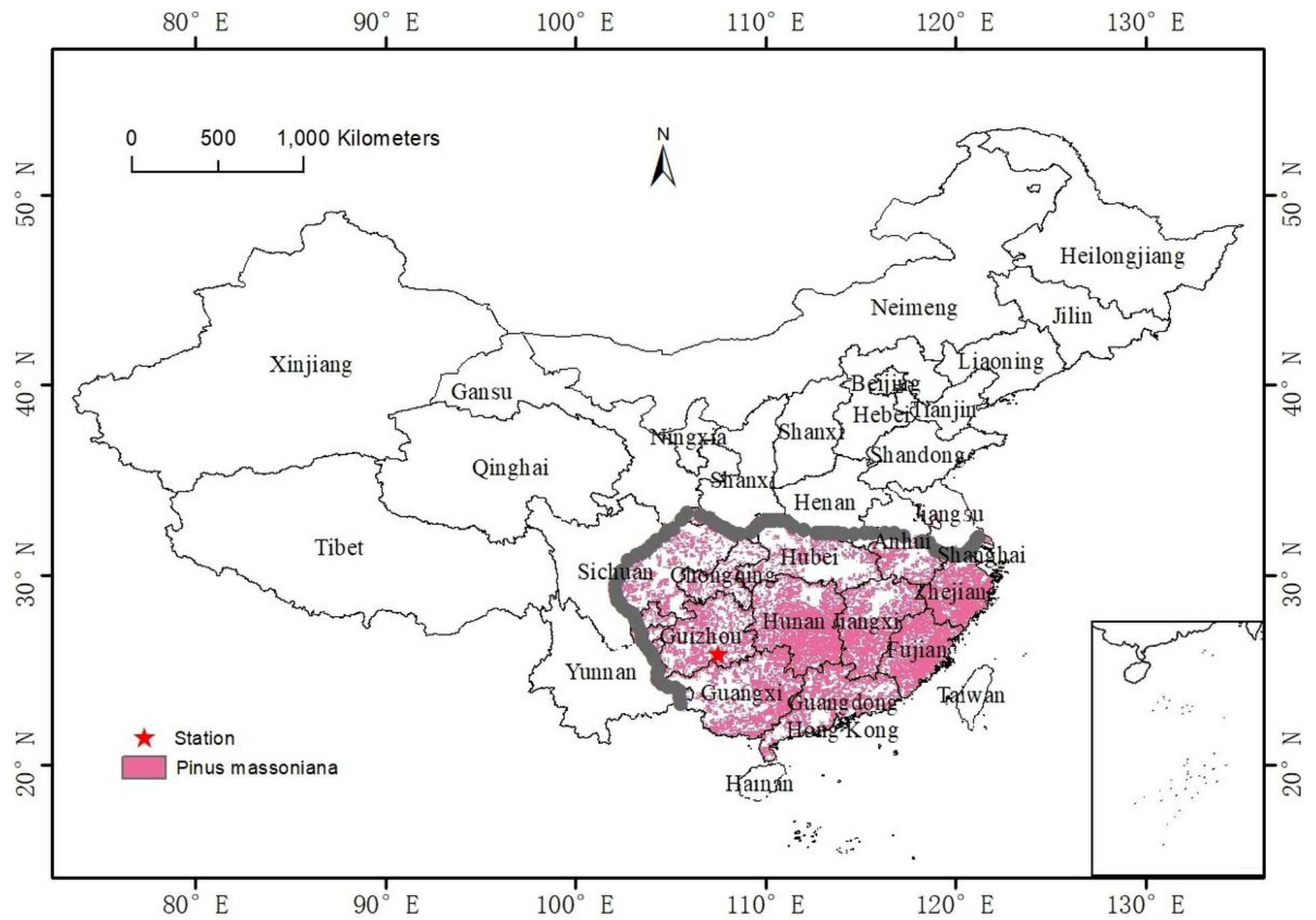

Figure 1

Distribution of Pinus massoniana in Mainland China. This figure was drawn based on Zhou[1], Lin[2], Zhang[3], and Yan[4]. The Taiwan and Sansha regions were not included in this study. On Hainan Island, there are variants of Pinus massoniana which were also not included in the study. The study site is indicated by a red star. Note: The designations employed and the presentation of the material on this map do not imply the expression of any opinion whatsoever on the part of Research Square concerning the legal status of any country, territory, city or area or of its authorities, or concerning the delimitation of its frontiers or boundaries. This map has been provided by the authors. 

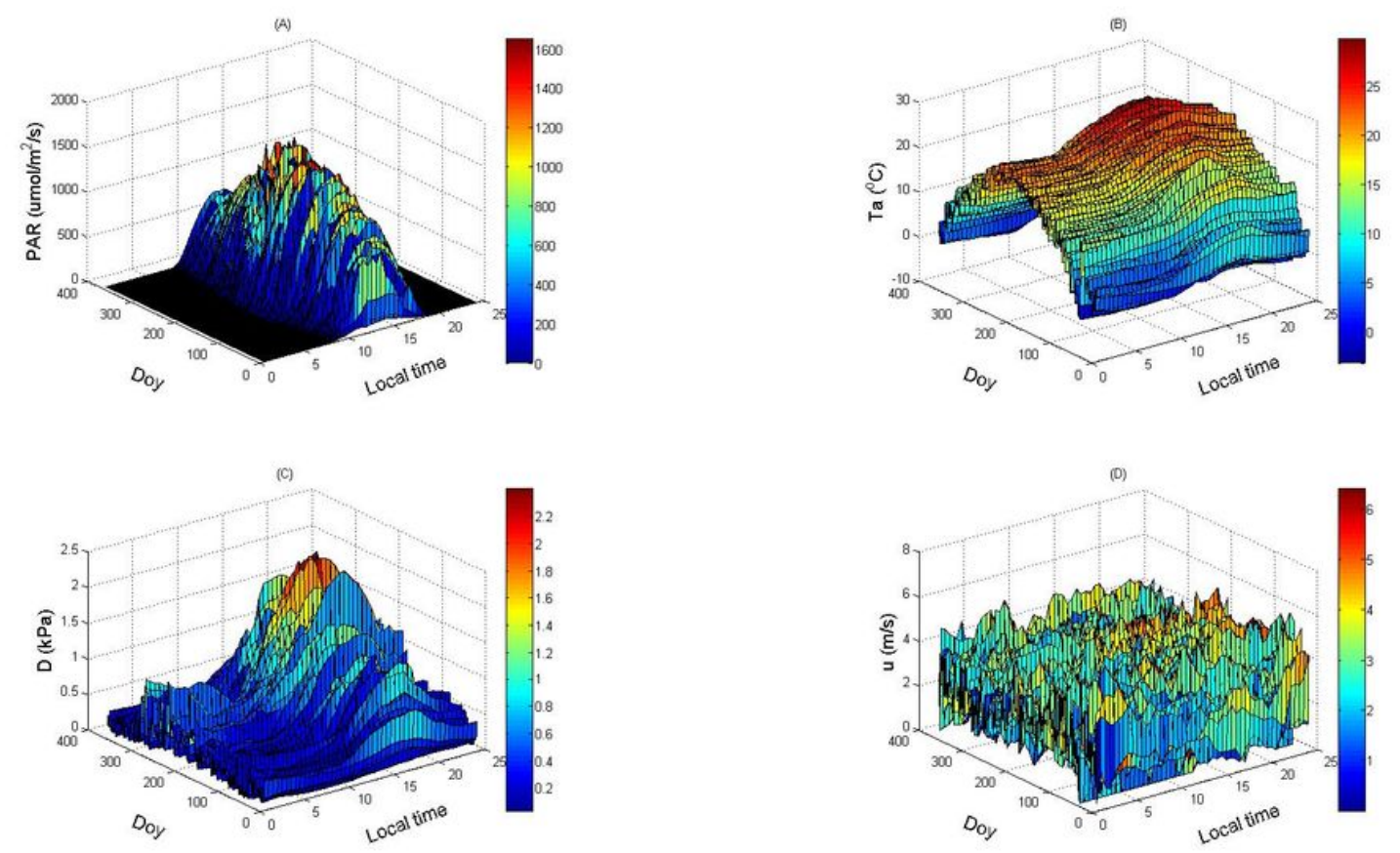

Figure 2

Microclimate of the studied pure Pinus massoniana plantations. (A) photosynthetically active radiation, PAR; (B) air temperature at $30 \mathrm{~m}$ height, Ta; (C) water vapor pressure deficit at $30 \mathrm{~m}$ height, $\mathrm{D}$; (D) and wind speed at $30 \mathrm{~m}$ height, $\mathrm{u}$.

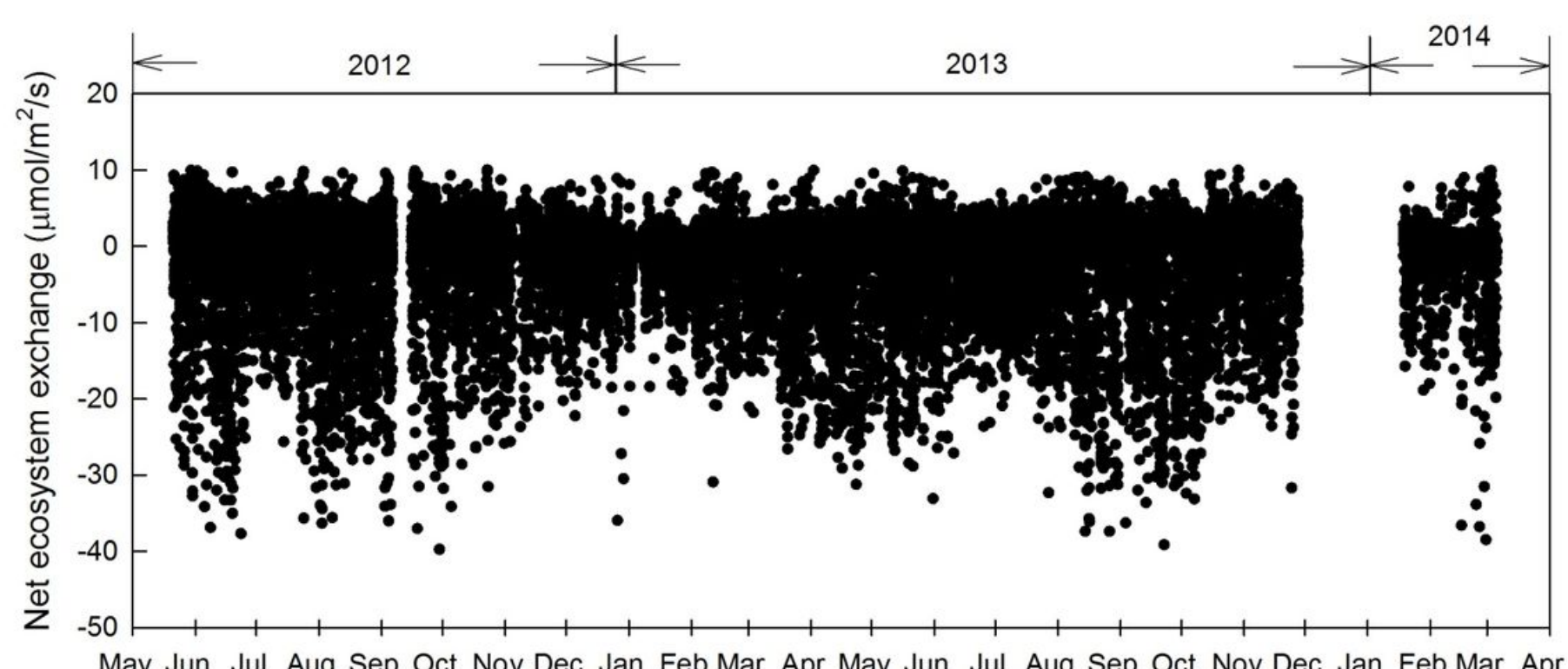

Time series (Half hourly data) 
Figure 3

Time series of net ecosystem exchanges before gap filling in 30 min intervals.

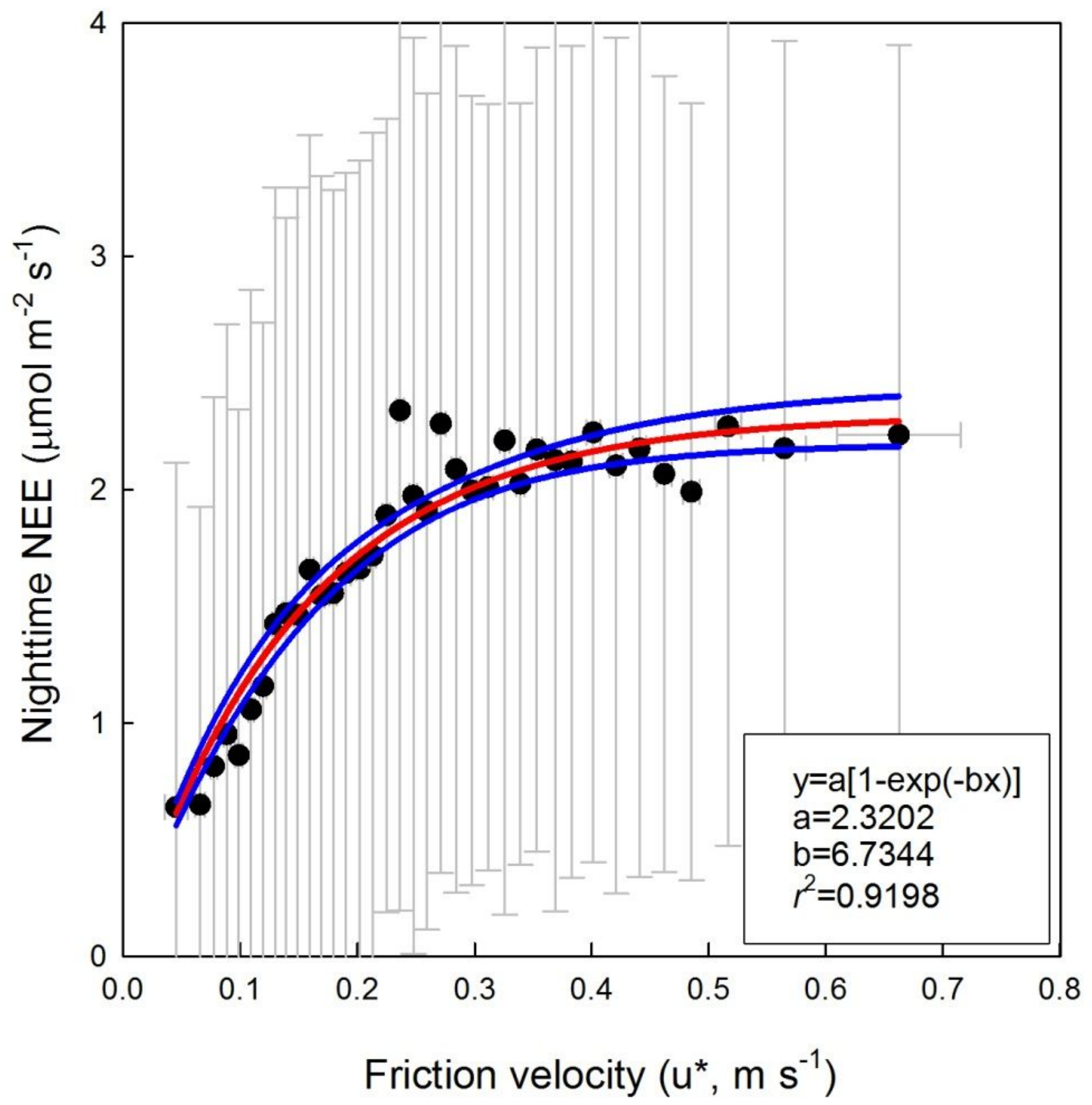

Figure 4

Dependence of nighttime net ecosystem exchange (NEE) on friction velocity $\left(u^{\star}\right)$. The data were binned as the same number of data points per bin after sorting as $u^{\star}$. The mean value (black circles) and standard deviation (error bars) of each bin were calculated. An exponential growth to maximum equation was fitted to the dataset. 

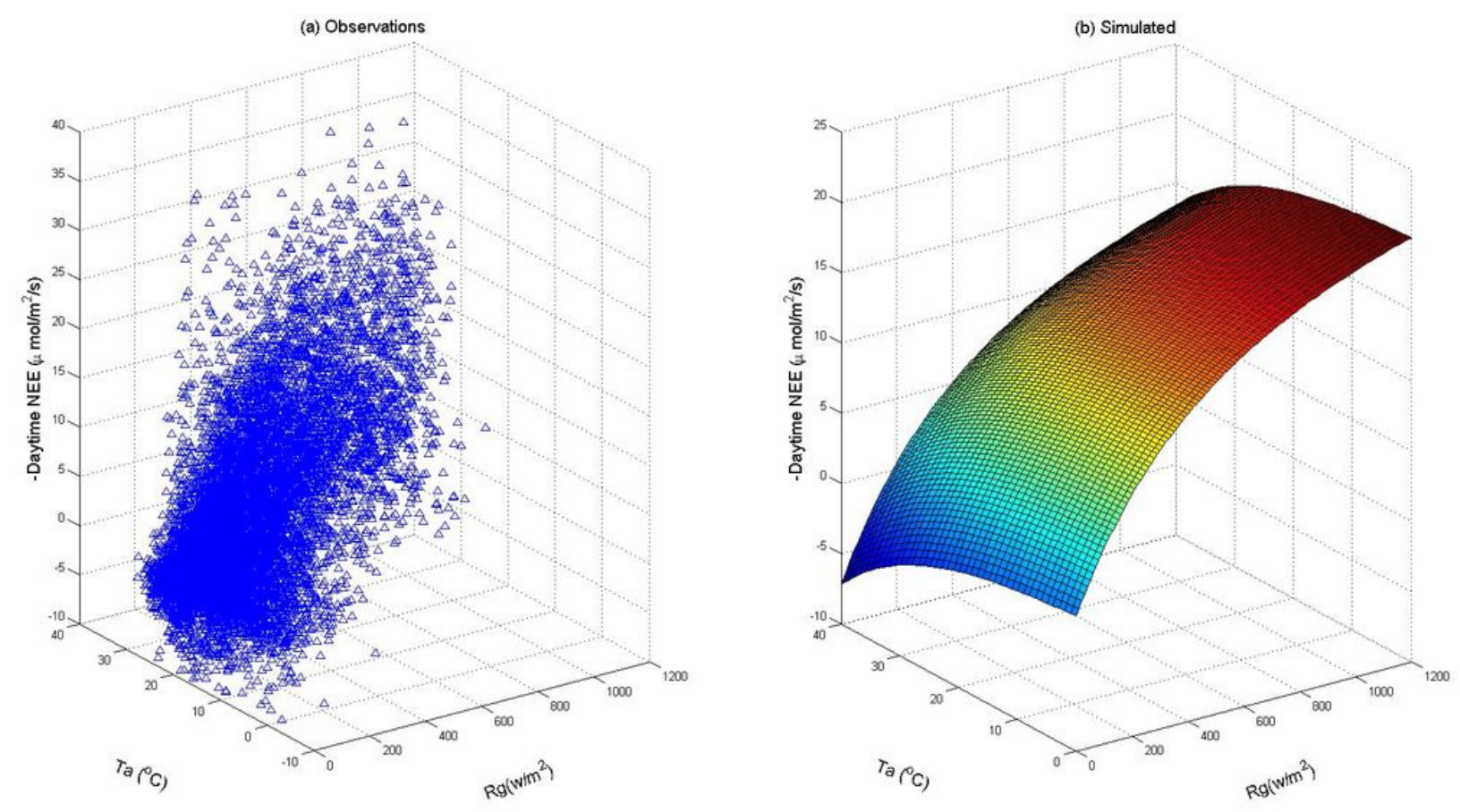

Figure 5

Co-control of solar radiation (Rg) and air temperature (Ta) on daytime net ecosystem exchange (NEE). Subpanel (a) shows our observations, and (b) shows the simulated results.

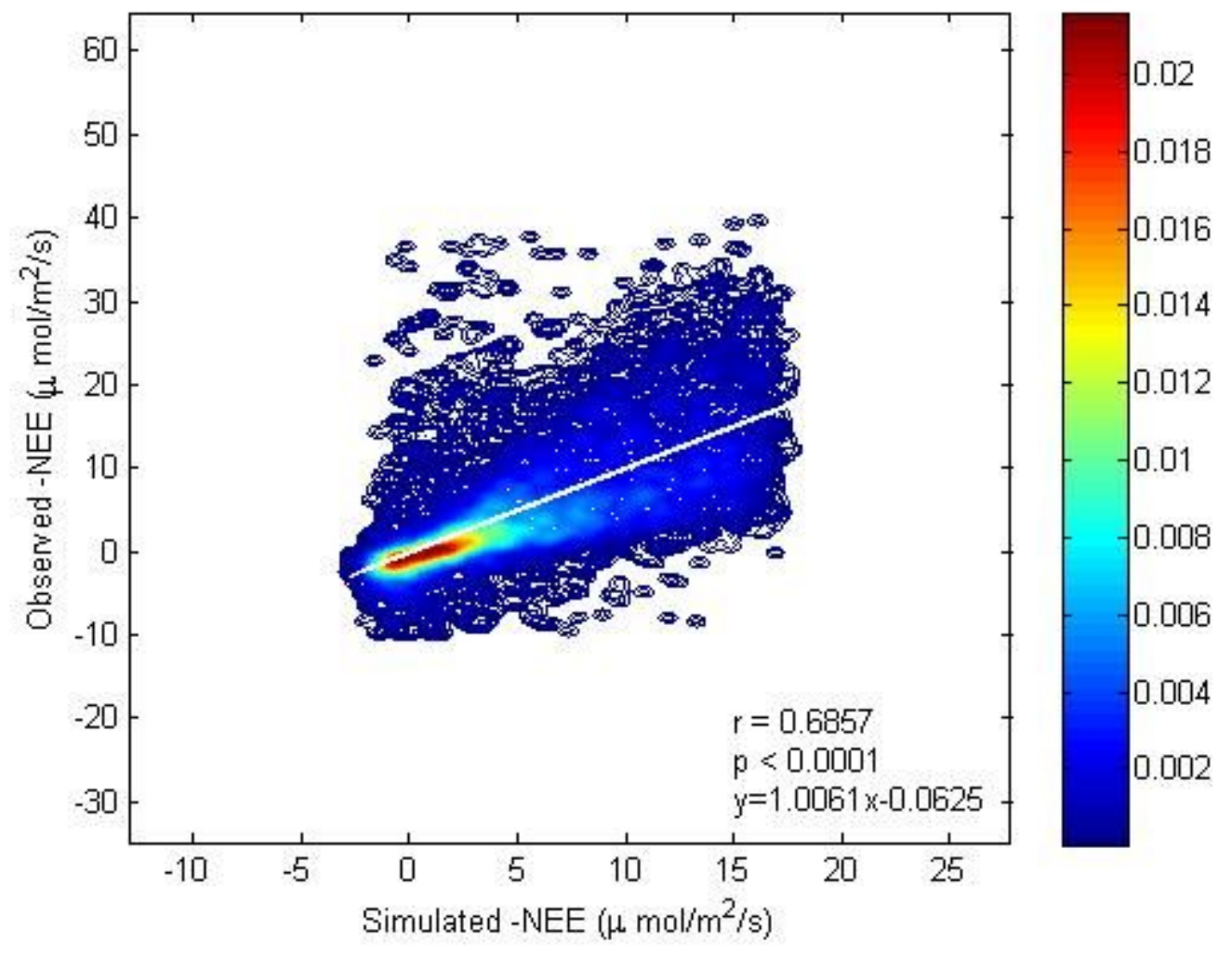

Figure 6 
Observed and simulated daytime net ecosystem exchanges (NEE) for the investigated Masson pine evenaged pure stand. Kernel density plot was used to show the distribution of data points. Linear regression was performed as shown by the white line.

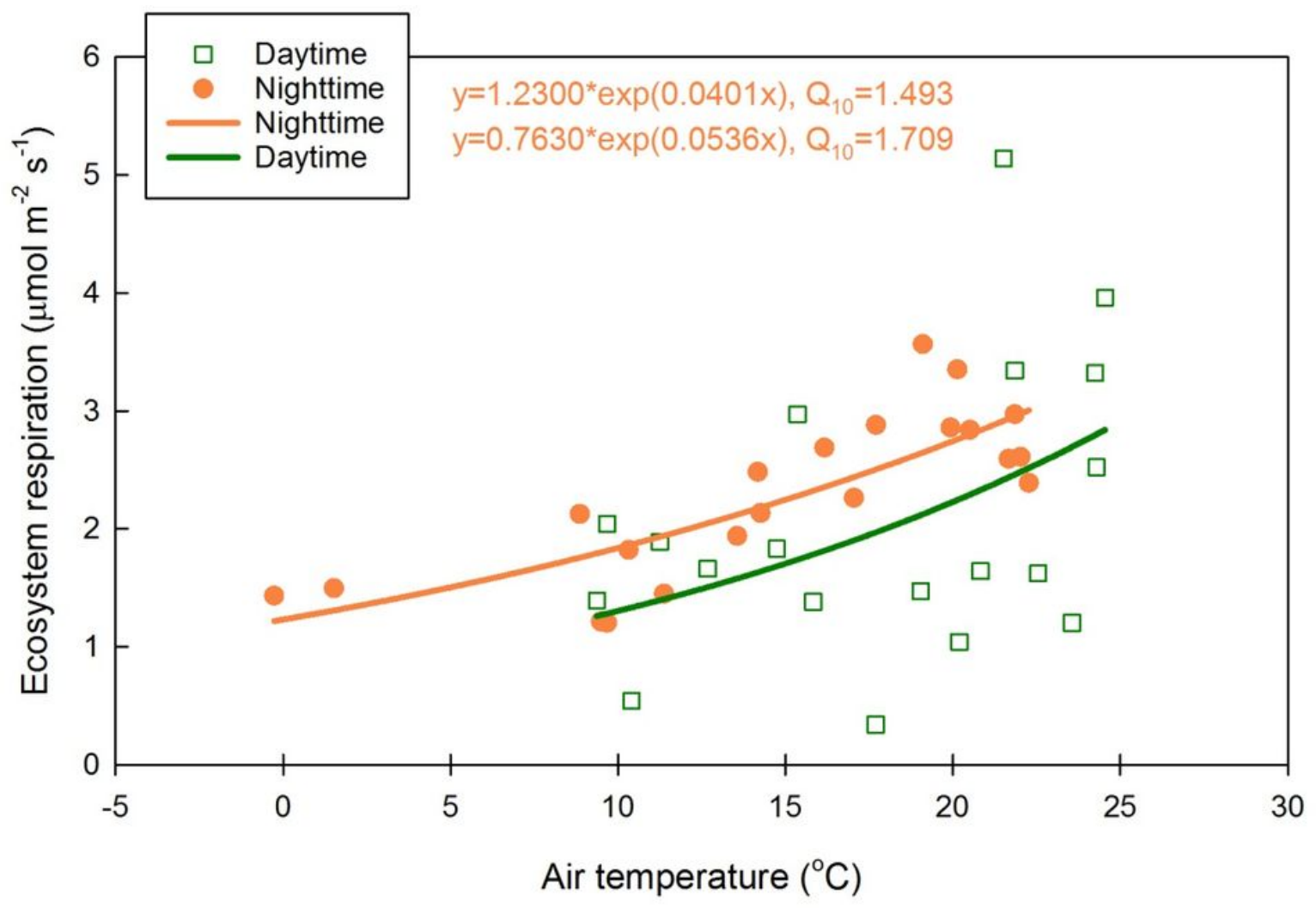

Figure 7

Dependence of daytime dark respiration (green open squares) and nighttime respiration (red solid circles) on air temperature. The van't Hoff model was fitted to the data. 


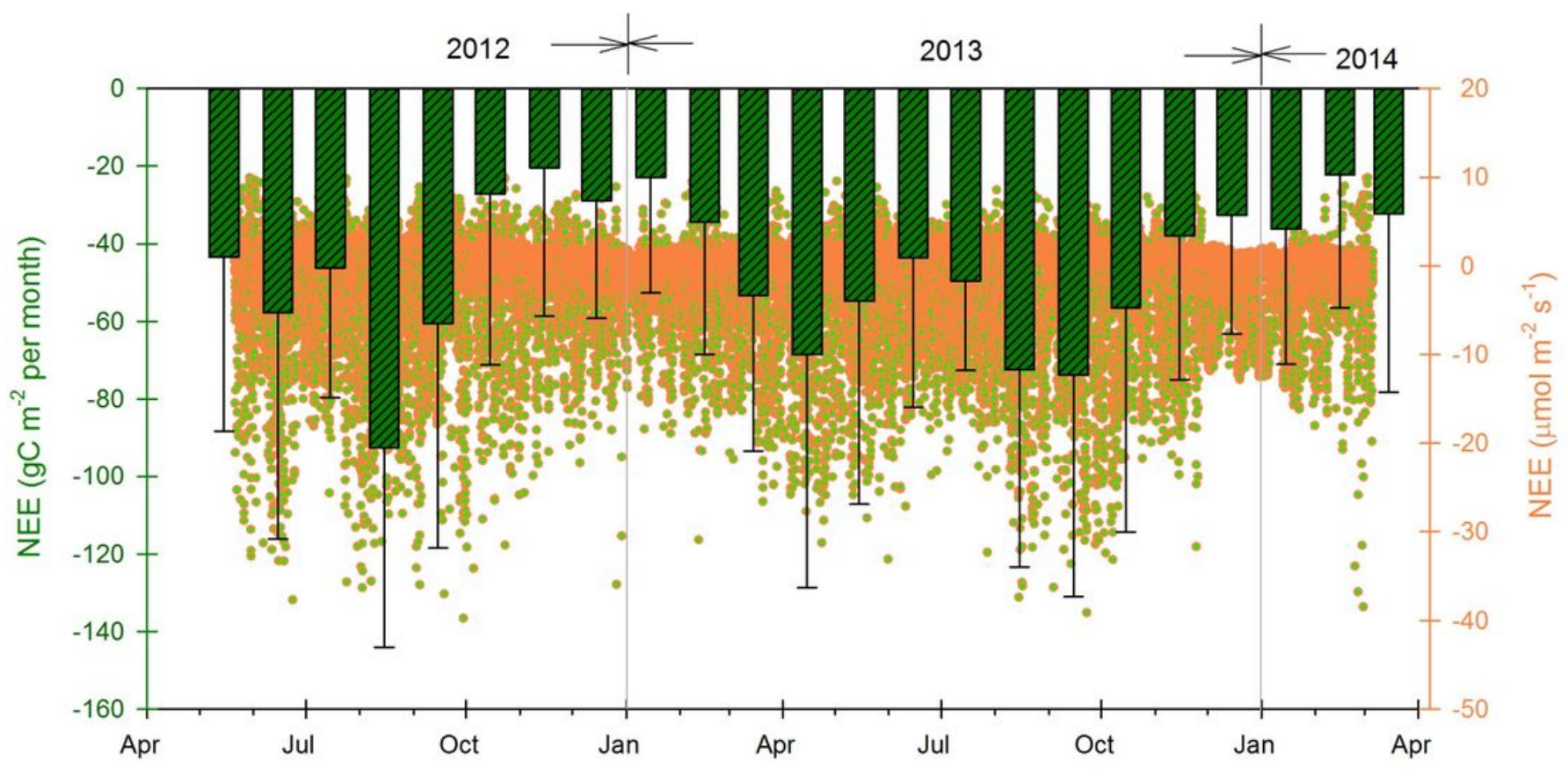

Figure 8

Time series of net ecosystem exchanges after gap filling. The circles show the half-hourly data, and bars with error bars indicate monthly values and their standard deviations. 

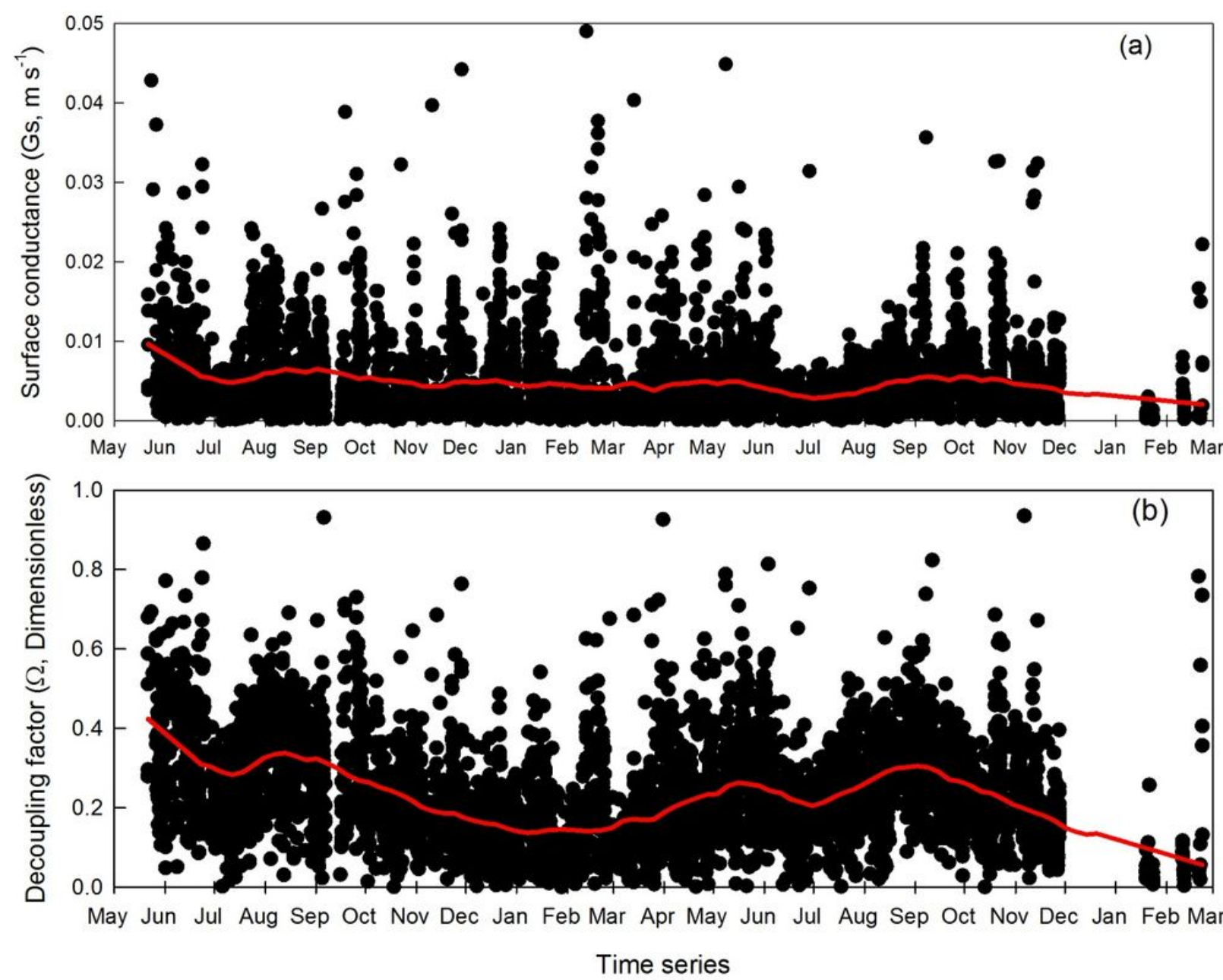

Figure 9

Time series of surface conductance (Gs) derived by inverting the Penman-Monteith equation (a) and the decoupling factor $(\Omega, b)$. The red lines are smoothing lines illustrating the general trend. 
(a)
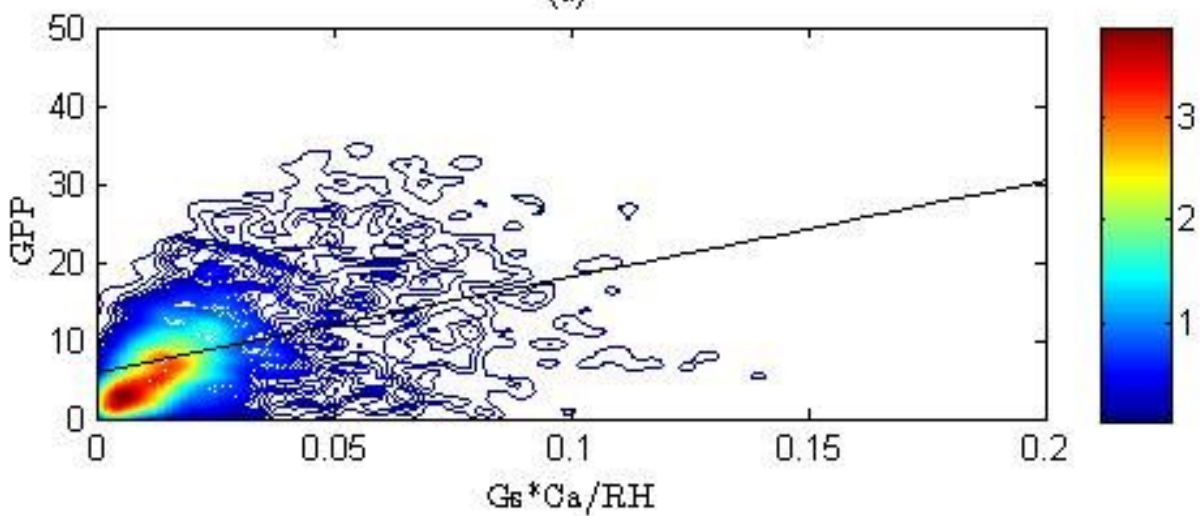

(b)
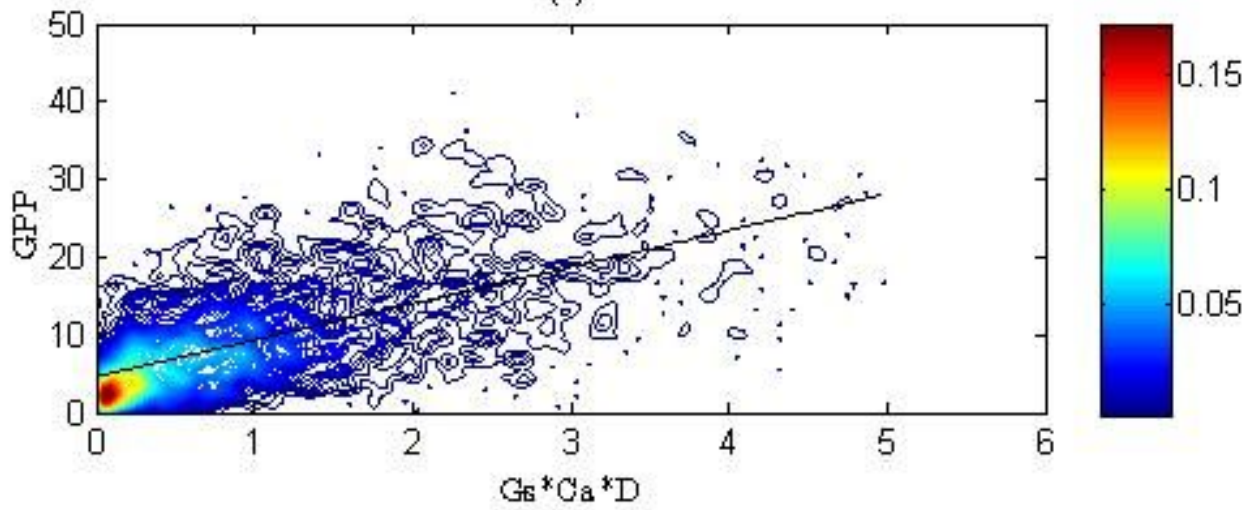

(c)
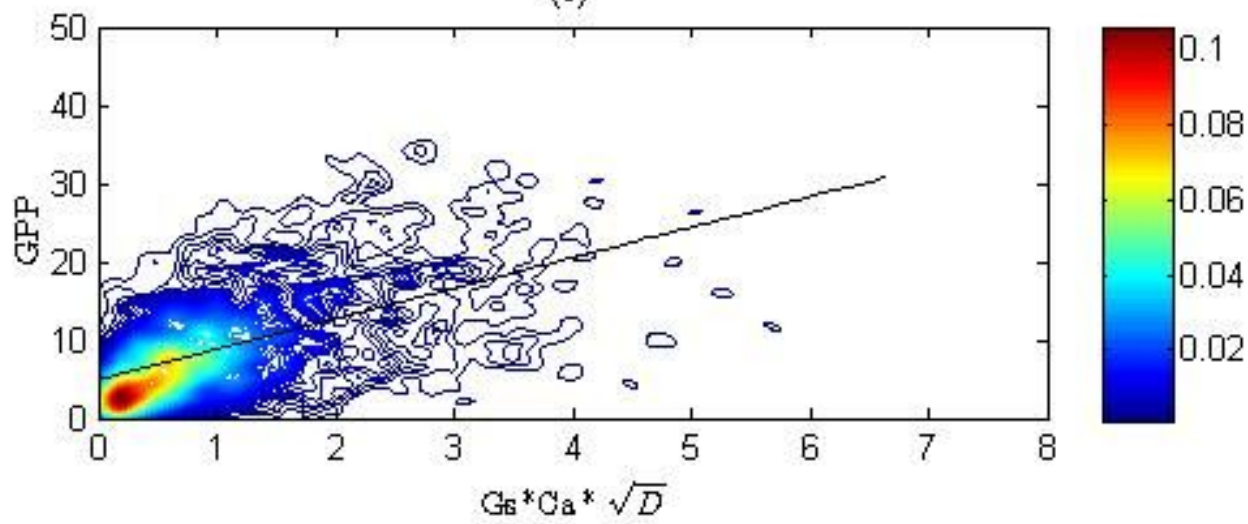

Figure 10

Gross primary production (GPP) expressed as a function of surface conductance (Gs) and water vapor deficit (D) or relative humidity (RH). GPP is expressed in $\mu \mathrm{mol} m-2 \mathrm{~s}-1$, Gs is expressed in $\mathrm{m} \mathrm{s-1,Ca}$ is the ambient carbon dioxide concentration and is expressed in $\mathrm{ppm}, \mathrm{RH}$ is expressed in \%, and $\mathrm{D}$ is expressed in $\mathrm{kPa}$. Linear regression was applied to the dataset, which is indicated by the black line ((a) $y=122.6700+5.8480, r 2=0.1967 ;$ (b) $y=4.6969 x+4.6071, r 2=0.4148 ;$ (c) $y=3.9000 x+4.9045, r 2=0.3235$.

\section{Supplementary Files}


This is a list of supplementary files associated with this preprint. Click to download.

- SupportMaterial.docx 